\title{
Trans-ancestry genetic study of type 2 diabetes highlights the power of diverse populations for discovery and translation
}

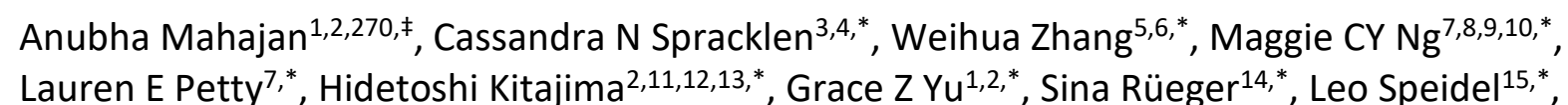
Young Jin $\mathrm{Kim}^{16}$, Momoko Horikoshi ${ }^{17}$, Josep M Mercader ${ }^{18,19,20}$, Daniel Taliun ${ }^{21}$, Sanghoon Moon $^{16}$, Soo-Heon Kwak ${ }^{22}$, Neil R Robertson ${ }^{1,2}$, Nigel W Rayner ${ }^{1,2,23,24}$, Marie Loh ${ }^{5,25,26}$, BongJo Kim ${ }^{16}$, Joshua Chiou ${ }^{27}$, Irene Miguel-Escalada ${ }^{28,29}$, Pietro della Briotta Parolo ${ }^{14}$, Kuang $\mathrm{Lin}^{30}$, Fiona Bragg ${ }^{30}$, Michael H Preuss ${ }^{31}$, Fumihiko Takeuchi ${ }^{32}$, Jana Nano ${ }^{33}$, Xiuqing Guo ${ }^{34}$, Amel Lamri ${ }^{35,36}$, Masahiro Nakatochi ${ }^{37}$, Robert A Scott ${ }^{38}$, Jung-Jin Lee ${ }^{39}$, Alicia HuertaChagoya ${ }^{40}$, Mariaelisa Graff ${ }^{41}$, Jin-Fang Chai ${ }^{42}$, Esteban J Parra ${ }^{43}$, Jie Yao ${ }^{34}$, Lawrence F Bielak $^{44}$, Yasuharu Tabara ${ }^{45}$, Yang Hai ${ }^{34}$, Valgerdur Steinthorsdottir ${ }^{46}$, James P Cook ${ }^{47}$, Mart Kals $^{48}$, Niels Grarup ${ }^{49}$, Ellen M Schmidt ${ }^{21}$, Ian Pan ${ }^{50}$, Tamar Sofer ${ }^{51,52,53}$, Matthias Wuttke ${ }^{54}$, Chloe Sarnowski ${ }^{55}$, Christian Gieger ${ }^{56,57}$, Darryl Nousome ${ }^{58}$, Stella Trompet ${ }^{59,60}$, Jirong Long ${ }^{61}$, Meng Sun ${ }^{2}$, Lin Tong62, Wei-Min Chen ${ }^{63}$, Meraj Ahmad ${ }^{64}$, Raymond Noordam ${ }^{60}$, Victor JY Lim $^{42}$, Claudia HT Tam ${ }^{65,66}$, Yoonjung Yoonie Joo ${ }^{67,68}$, Chien-Hsiun Chen ${ }^{69}$, Laura M Raffield ${ }^{3}$, Cécile Lecoeur ${ }^{70}$, Nisa M Maruthur ${ }^{71,72}$, Bram Peter Prins ${ }^{23}$, Aude Nicolas ${ }^{73}$, Lisa R Yanek ${ }^{72}$, Guanjie Chen ${ }^{74}$, Richard A Jensen ${ }^{75}$, Salman Tajuddin ${ }^{76}$, Edmond Kabagambe ${ }^{61}$, Ping An ${ }^{77}$, Anny H Xiang ${ }^{78}$, Hyeok Sun Choi ${ }^{79}$, Brian E Cade ${ }^{52,20}$, Jingyi Tan ${ }^{34}$, Fernando Abaitua ${ }^{2}$, Linda S Adair $^{80}$, Adebowale Adeyemo ${ }^{74}$, Carlos A Aguilar-Salinas ${ }^{81}$, Masato Akiyama ${ }^{82,83}$, Sonia S Anand $^{35,36,84}$, Alain Bertoni ${ }^{85}$, Zheng Bian ${ }^{86}$, Jette Bork-Jensen ${ }^{49}$, Ivan Brandslund ${ }^{87,88}$, Jennifer A Brody ${ }^{75}$, Chad M Brummett ${ }^{89}$, Thomas A Buchanan ${ }^{90}$, Mickaël Canouil ${ }^{70}$, Juliana CN Chan ${ }^{65,66,91,92}$, Li-Ching Chang ${ }^{69}$, Miao-Li Chee ${ }^{93}$, Ji Chen ${ }^{94}$, Shyh-Huei Chen ${ }^{95}$, Yuan-Tsong Chen $^{69}$, Zhengming Chen ${ }^{30,96}$, Lee-Ming Chuang ${ }^{97,98}$, Mary Cushman ${ }^{99}$, Swapan K Das ${ }^{100}, \mathrm{H}$. Janaka de Silva ${ }^{101}$, George Dedoussis ${ }^{102}$, Latchezar Dimitrov ${ }^{8}$, Ayo P Doumatey ${ }^{74}$, Shufa Du ${ }^{80}$, Qing Duan ${ }^{3}$, Kai-Uwe Eckardt ${ }^{103,104}$, Leslie S Emery ${ }^{105}$, Daniel S Evans ${ }^{106}$, Michele K Evans ${ }^{76}$, Krista Fischer ${ }^{48}$, James S Floyd ${ }^{75}$, Ian Ford ${ }^{107}$, Myriam Fornage ${ }^{108}$, Oscar H Franco ${ }^{33}$, Timothy M Frayling ${ }^{109}$, Barry I Freedman ${ }^{110}$, Christian Fuchsberger ${ }^{21,111}$, Pauline Genter ${ }^{112}$, Hertzel C Gerstein $35,36,84$, Vilmantas Giedraitis ${ }^{113}$, Clicerio González-Villalpando ${ }^{114}$, Maria Elena González-Villalpando ${ }^{114}$, Mark O Goodarzi ${ }^{115}$, Penny Gordon-Larsen ${ }^{80}$, David Gorkin ${ }^{116}$, Myron Gross ${ }^{117}$, Yu Guo 86 , Sophie Hackinger ${ }^{23}$, Sohee Han ${ }^{16}$, Andrew T Hattersley ${ }^{118}$, Christian Herder ${ }^{56,119,120}$, Annie-Green Howard ${ }^{121}$, Willa Hsueh ${ }^{122}$, Mengna Huang ${ }^{50,123}$, Wei Huang $^{124}$, Yi-Jen Hung ${ }^{125,126}$, Mi Yeong Hwang ${ }^{16}$, Chii-Min Hwu ${ }^{127,128}$, Sahoko Ichihara ${ }^{129}$, Mohammad Arfan Ikram ${ }^{33}$, Martin Ingelsson ${ }^{113}$, Md. Tariqul Islam ${ }^{130}$, Masato Isono ${ }^{32}$, HyeMi Jang ${ }^{16}$, Farzana Jasmine ${ }^{62}$, Guozhi Jiang ${ }^{65,66}$, Jost B Jonas ${ }^{131}$, Marit E Jørgensen ${ }^{132,133}$, Torben Jørgensen ${ }^{134,135,136}$, Yoichiro Kamatani ${ }^{82,137}$, Fouad R Kandeel ${ }^{138}$, Anuradhani Kasturiratne ${ }^{139}$, Tomohiro Katsuya ${ }^{140,141}$, Varinderpal Kaur ${ }^{19}$, Takahisa Kawaguchi ${ }^{45}$, Jacob M Keaton $^{8,61}$, Abel N Kho ${ }^{142,143}$, Chiea-Chuen Khor ${ }^{144,145}$, Muhammad G Kibriya ${ }^{62}$, Duk-Hwan $\operatorname{Kim}^{146}$, Katsuhiko Kohara ${ }^{147}$, Jennifer Kriebel ${ }^{56,57}$, Florian Kronenberg ${ }^{148}$, Johanna Kuusisto ${ }^{149}$, Kristi Läll ${ }^{48,150}$, Leslie A Lange ${ }^{151}$, Myung-Shik Lee ${ }^{152,153}$, Nanette R Lee ${ }^{154}$, Aaron Leong ${ }^{155,156}$, Liming $\mathrm{Li}^{157}$, Yun Li ${ }^{3}$, Ruifang Li-Gao ${ }^{158}$, Symen Ligthart ${ }^{33}$, Cecilia M Lindgren ${ }^{2,159,160}$, Allan Linneberg ${ }^{134,161}$, Ching-Ti Liu ${ }^{55}$, Jianjun Liu' ${ }^{144,162}$, Adam E Locke ${ }^{163,164}$, Tin Louie ${ }^{105}$, Jian'an Luan $^{38}$, Andrea O Luk ${ }^{65,66}$, Xi Luo ${ }^{165}$, Jun Lv ${ }^{157}$, Valeriya Lyssenko ${ }^{166,167}$, Vasiliki Mamakou ${ }^{168}$, K

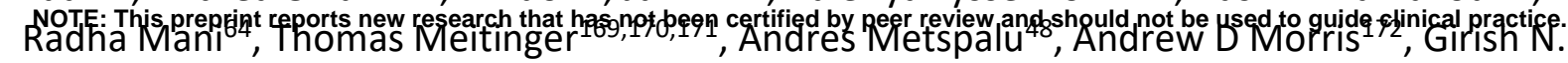


medRxiv preprint doi: https://doi.org/10.1101/2020.09.22.20198937; this version posted September 23,2020 . The copyright holder for this preprint (which was not certified by peer review) is the author/funder, who has granted medRxiv a license to display the preprint in perpetuity.

It is made available under a CC-BY 4.0 International license.

Nadkarni ${ }^{31,173}$, Jerry L Nadler ${ }^{174}$, Michael A Nalls ${ }^{73,175,176}$, Uma Nayak ${ }^{63}$, loanna Ntalla ${ }^{177}$, Yukinori Okada ${ }^{178,179}$, Lorena Orozco ${ }^{180}$, Sanjay R Patel ${ }^{181}$, Mark A Pereira ${ }^{182}$, Annette Peters $^{56,57,171}$, Fraser J Pirie ${ }^{183}$, Bianca Porneala ${ }^{156}$, Gauri Prasad ${ }^{184,185}$, Sebastian Preiss| ${ }^{116}$, Laura J Rasmussen-Torvik ${ }^{186}$, Alexander P Reiner ${ }^{187}$, Michael Roden ${ }^{56,119,120}$, Rebecca Rohde $^{41}$, Katheryn Roll ${ }^{34}$, Charumathi Sabanayagam ${ }^{93,188,189}$, Maike Sander ${ }^{190,191,192}$, Kevin Sandow $^{34}$, Naveed Sattar ${ }^{193}$, Sebastian Schönherr ${ }^{148}$, Claudia Schurmann ${ }^{31,173,194}$, Mohammad Shahriar ${ }^{62}$, Jinxiu Shi ${ }^{124}$, Dong Mun Shin ${ }^{16}$, Daniel Shriner ${ }^{74}$, Jennifer A Smith ${ }^{44,195}$, Wing Yee So ${ }^{65,91}$, Alena Stančáková ${ }^{149}$, Adrienne M Stilp ${ }^{105}$, Konstantin Strauch ${ }^{196,197}$, Ken Suzuki ${ }^{17,82,178,198}$, Atsushi Takahashi ${ }^{82,199}$, Kent D Taylor ${ }^{34}$, Barbara Thorand $^{56,57}$, Gudmar Thorleifsson ${ }^{46}$, Unnur Thorsteinsdottir ${ }^{46,200}$, Brian Tomlinson ${ }^{65,201}$, Jason M Torres², Fuu-Jen Tsai202, Jaakko Tuomilehto ${ }^{203,204,205,206}$, Teresa Tusie-Luna207,208, Miriam S Udler ${ }^{18,19,155}$, Adan Valladares-Salgado ${ }^{209}$, Rob M van Dam ${ }^{42,162,210}$, Jan B van Klinken ${ }^{211,212,213}$, Rohit Varma ${ }^{214}$, Marijana Vujkovic ${ }^{215}$, Niels Wacher-Rodarte ${ }^{216}$, Ellie Wheeler ${ }^{38,94}$, Eric A Whitse ${ }^{41,217}$, Ananda R Wickremasinghe ${ }^{139}$, Konstantin Willems van Dijk $^{211,212,218}$, Daniel R Witte 219,220 , Chittaranjan S Yajnik ${ }^{221}$, Ken Yamamoto ${ }^{222}$, Toshimasa Yamauchi ${ }^{198}$, Loïc Yengo ${ }^{70,223}$, Kyungheon Yoon ${ }^{16}$, Canqing Yu ${ }^{157}$, Jian-Min Yuan ${ }^{224,225}$, Salim Yusuf ${ }^{35,36,84}$, Liang Zhang ${ }^{93}$, Wei Zheng ${ }^{61}$, FinnGen ${ }^{271}$, Leslie J Raffel ${ }^{226}$, Michiya Igase ${ }^{227}$, Eli Ipp $^{112}$, Susan Redline ${ }^{52,20,228}$, Yoon Shin Cho ${ }^{79}$, Lars Lind ${ }^{229}$, Michael A Province ${ }^{77}$, Craig L Hanis $^{230}$, Patricia A Peyser ${ }^{44}$, Erik Ingelsson ${ }^{231,232}$, Alan B Zonderman ${ }^{76}$, Bruce M Psaty ${ }^{75,233}$, Ya-Xing Wang ${ }^{234}$, Charles N Rotimi ${ }^{74}$, Diane M Becker ${ }^{72}$, Fumihiko Matsuda ${ }^{45}$, Yongmei Liu $^{85,235}$, Eleftheria Zeggini ${ }^{23,24,236}$, Mitsuhiro Yokota ${ }^{237}$, Stephen S Rich ${ }^{238}$, Charles Kooperberg ${ }^{187}$, James S Pankow ${ }^{182}$, James C Engert ${ }^{239,240}$, Yii-Der Ida Chen ${ }^{34}$, Philippe Froguel $^{70,241}$, James G Wilson ${ }^{242}$, Wayne HH Sheu ${ }^{126,128,243}$, Sharon LR Kardia ${ }^{44}$, Jer-Yuarn Wu ${ }^{69}$, M Geoffrey Hayes ${ }^{67,244,245}$, Ronald CW Ma65,66,91,92, Tien-Yin Wong ${ }^{93,188,189}$, Leif Groop $^{14,166}$, Dennis O Mook-Kanamori ${ }^{158}$, Giriraj R Chandak ${ }^{64}$, Francis S Collins ${ }^{246}$, Dwaipayan Bharadwaj ${ }^{184,247}$, Guillaume Paré ${ }^{36,248}$, Michèle M Sale ${ }^{63}$, Habibul Ahsan ${ }^{62}$, Ayesha A Motala ${ }^{183}$, Xiao-Ou Shu ${ }^{61}$, Kyong-Soo Park ${ }^{22,249,250}$, J Wouter Jukema ${ }^{59,211}$, Miguel Cruz ${ }^{209}$, Roberta McKean-Cowdin ${ }^{58}$, Harald Grallert ${ }^{56,57,251,252}$, Ching-Yu Cheng ${ }^{93,188,189}$, Erwin P Bottinger ${ }^{31,173,194}$, Abbas Dehghan ${ }^{5,33,253}$, E-Shyong Tai ${ }^{42,162,254}$, Josee Dupuis ${ }^{55}$, Norihiro Kato $^{32}$, Markku Laakso ${ }^{149}$, Anna Köttgen ${ }^{54}$, Woon-Puay Koh ${ }^{42,255}$, Colin NA Palmer ${ }^{256}$, Simin Liu $^{50,123,257}$, Goncalo Abecasis ${ }^{21}$, Jaspal S Kooner ${ }^{6,253,258,259}$, Ruth JF Loos ${ }^{31,260}$, Kari E North ${ }^{41}$, Christopher A Haiman ${ }^{58}$, Jose C Florez ${ }^{18,19,155}$, Danish Saleheen ${ }^{39,261,262}$, Torben Hansen ${ }^{49}$, Oluf Pedersen ${ }^{49}$, Reedik Mägi ${ }^{48}$, Claudia Langenberg ${ }^{38}$, Nicholas J Wareham ${ }^{38}$, Shiro Maeda ${ }^{17,263,264}$, Takashi Kadowaki ${ }^{198}$, Juyoung Lee ${ }^{16}$, Iona Y Millwood ${ }^{30,96}$, Robin G Walters $^{30,96}$, Kari Stefansson ${ }^{46,200}$, Simon R Myers ${ }^{2,15}$, Jorge Ferrer ${ }^{28,29,265}$, Kyle J

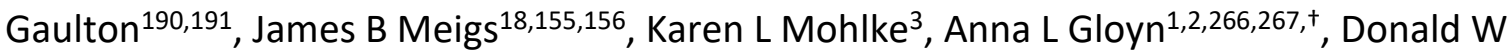
Bowden $^{8,9,268,{ }^{+}}$, Jennifer E Below ${ }^{7,{ }^{+}}$, John C Chambers ${ }^{5,6,25,253,258,{ }^{+}}$Xueling Sim ${ }^{42,{ }^{+}}$, Michael Boehnke ${ }^{21,{ }^{\dagger}}$, Jerome I Rotter ${ }^{34,+}$, Mark I McCarthy ${ }^{1,2,266,270,+, \ddagger}$, Andrew P Morris ${ }^{2,47,48,269,+, \neq}$, on behalf of the DIAMANTE Consortium.

${ }^{1}$ Oxford Centre for Diabetes, Endocrinology and Metabolism, Radcliffe Department of Medicine, University of Oxford, Oxford, UK. ${ }^{2}$ Wellcome Centre for Human Genetics, Nuffield Department of Medicine, University of Oxford, Oxford, UK. ${ }^{3}$ Department of Genetics, University of North Carolina at Chapel Hill, Chapel Hill, NC, USA. ${ }^{4}$ Department of Epidemiology and Biostatistics, University of Massachusetts-Amherst, Amherst, MA, USA. ${ }^{5}$ Department of Epidemiology and Biostatistics, Imperial College London, London, UK. ${ }^{6}$ Department of Cardiology, Ealing Hospital, London North West Healthcare NHS Trust, London, UK. ${ }^{7}$ Vanderbilt Genetics Institute, Vanderbilt University Medical Center, Nashville, TN, USA. ${ }^{8}$ Center for Genomics and Personalized Medicine Research, Wake Forest School of Medicine, Winston-Salem, NC, USA. ${ }^{9}$ Department of Biochemistry, Wake Forest School of Medicine, Winston-Salem, NC, USA. ${ }^{10}$ Division of Genetic Medicine, Vanderbilt 
medRxiv preprint doi: https://doi.org/10.1101/2020.09.22.20198937; this version posted September 23, 2020. The copyright holder for this preprint (which was not certified by peer review) is the author/funder, who has granted medRxiv a license to display the preprint in

perpetuity.
It is made available under a CC-BY 4.0 International license .

University Medical Center, Nashville, TN, USA. ${ }^{11}$ The Advanced Research Center for Innovations in NextGeneration Medicine (INGEM), Tohoku University, Sendai, Japan. ${ }^{12}$ Department of Integrative Genomics, Tohoku Medical Megabank Organization, Tohoku University, Sendai, Japan. ${ }^{13}$ Cancer Center, Tohoku University Hospital, Tohoku University, Sendai, Japan. ${ }^{14}$ Finnish Institute for Molecular Medicine (FIMM), University of Helsinki, Helsinki, Finland. ${ }^{15}$ Department of Statistics, University of Oxford, Oxford, UK. ${ }^{16}$ Division of Genome Research, Center for Genome Science, National Institute of Health, Cheongju-si, Korea. ${ }^{17}$ Laboratory for Endocrinology, Metabolism and Kidney Diseases, RIKEN Centre for Integrative Medical Sciences, Yokohama, Japan. ${ }^{18}$ Programs in Metabolism and Medical \& Population Genetics, Broad Institute of Harvard and MIT, Cambridge, MA, USA. ${ }^{19}$ Diabetes Unit and Center for Genomic Medicine, Massachusetts General Hospital, Boston, MA, USA.. ${ }^{20}$ Harvard Medical School, Boston, MA, USA. ${ }^{21}$ Department of Biostatistics and Center for Statistical Genetics, University of Michigan, Ann Arbor, MI, USA. ${ }^{22}$ Department of Internal Medicine, Seoul National University Hospital, Seoul, South Korea. ${ }^{23}$ Department of Human Genetics, Wellcome Sanger Institute, Hinxton, UK. ${ }^{24}$ Institute of Translational Genomics, Helmholtz Zentrum München, German Research Center for Environmental Health, Neuherberg, Germany. ${ }^{25}$ Lee Kong Chian School of Medicine, Nanyang Technological University, Singapore, Singapore. ${ }^{26}$ Translational Laboratory in Genetic Medicine (TLGM), Agency for Science, Technology and Research (A*STAR) and National University of Singapore (NUS), Singapore, Singapore. ${ }^{27}$ Biomedical Sciences Graduate Studies Program, University of California San Diego, La Jolla, CA, USA. ${ }^{28}$ Regulatory Genomics and Diabetes, Centre for Genomic Regulation, The Barcelona Institute of Science and Technology, Barcelona, Spain. ${ }^{29}$ Centro de Investigación Biomédica en Red Diabetes y Enfermedades Metabólicas asociadas (CIBERDEM), Madrid, Spain. ${ }^{30}$ Nuffield Department of Population Health, University of Oxford, Oxford, UK. ${ }^{31}$ The Charles Bronfman Institute for Personalized Medicine, Icahn School of Medicine at Mount Sinai, New York, NY, USA. ${ }^{32}$ Department of Gene Diagnostics and Therapeutics, Research Institute, National Center for Global Health and Medicine, Tokyo, Japan. ${ }^{33}$ Department of Epidemiology, Erasmus University Medical Center, Rotterdam, The Netherlands. ${ }^{34}$ The Institute for Translational Genomics and Population Sciences, Department of Pediatrics, The Lundquist Institute for Biomedical Innovation (formerly Los Angeles Biomedical Research Institute) at Harbor-UCLA Medical Center, Torrance, CA, USA. ${ }^{35}$ Department of Medicine, McMaster University, Hamilton, ON, Canada. ${ }^{36}$ Population Health Research Institute, Hamilton Health Sciences and McMaster University, Hamilton, ON, Canada. ${ }^{37}$ Public Health Informatics Unit, Department of Integrated Health Sciences, Nagoya University Graduate School of Medicine, Nagoya, Japan. ${ }^{38} \mathrm{MRC}$ Epidemiology Unit, Institute of Metabolic Science, University of Cambridge, Cambridge, UK. ${ }^{39}$ Division of Translational Medicine and Human Genetics, University of Pennsylvania, Philadelphia, PA, USA. ${ }^{40}$ Consejo Nacional de Ciencia y Tecnología (CONACYT), Instituto Nacional de Ciencias Médicas y Nutrición Salvador Zubirán, Mexico City, Mexico. ${ }^{41}$ Department of Epidemiology, Gillings School of Global Public Health, University of North Carolina at Chapel Hill, Chapel Hill, NC, USA. ${ }^{42}$ Saw Swee Hock School of Public Health, National University of Singapore and National University Health System, Singapore, Singapore. ${ }^{43}$ Department of Anthropology, University of Toronto at Mississsauga, Mississauga, ON, Canada. ${ }^{44}$ Department of Epidemiology, School of Public Health, University of Michigan, Ann Arbor, MI, USA. ${ }^{45}$ Center for Genomic Medicine, Kyoto University Graduate School of Medicine, Kyoto, Japan. ${ }^{46}$ deCODE Genetics, Amgen inc., Reykjavik, Iceland. ${ }^{47}$ Department of Biostatistics, University of Liverpool, Liverpool, UK. ${ }^{48}$ Estonian Genome Center, Institute of Genomics, University of Tartu, Tartu, Estonia. ${ }^{49}$ The Novo Nordisk Foundation Center for Basic Metabolic Research, Faculty of Health and Medical Sciences, University of Copenhagen, Copenhagen, Denmark. ${ }^{50}$ Department of Epidemiology, Brown University School of Public Health, Providence, RI, USA. ${ }^{51}$ Department of Biostatistics, Harvard University, Boston, MA, USA. ${ }^{52}$ Division of Sleep and Circadian Disorders, Brigham and Women's Hospital, Boston, MA, USA. ${ }^{53}$ Department of Medicine, Harvard University, Boston, MA, USA. ${ }^{54}$ Institute of Genetic Epidemiology, Department of Biometry, Epidemiology, and Medical Bioinformatics, Faculty of Medicine and Medical Center, University of Freiburg, Freiburg, Germany. ${ }^{55}$ Department of Biostatistics, Boston University School of Public Health, Boston, MA, USA. ${ }^{56}$ German Center for Diabetes Research (DZD), Neuherberg, Germany. ${ }^{57}$ Institute of Epidemiology, Helmholtz Zentrum Munchen, German Research Center for Environmental Health, Neuherberg, Germany. ${ }^{58}$ Department of Preventive Medicine, Keck School of Medicine of USC, Los Angeles, CA, USA. ${ }^{59}$ Department of Cardiology, Leiden University Medical Center, Leiden, The Netherlands. ${ }^{60}$ Section of Gerontology and Geriatrics, Department of Internal Medicine, Leiden University Medical Center, Leiden, The Netherlands. ${ }^{61}$ Division of Epidemiology, Department of Medicine, Institute for Medicine and Public Health, Vanderbilt Genetics Institute, Vanderbilt University Medical Center, Nashville, TN, USA. ${ }^{62}$ Biological Sciences Division, Public Health Sciences, The University of Chicago, Chicago, IL, USA. ${ }^{63}$ Department of Public Health Sciences and Center for Public Health Genomics, University of Virginia School of Medicine, Charlottesville, VA, USA. ${ }^{64}$ Genomic Research on Complex Diseases (GRC-Group), CSIR-Centre for Cellular and Molecular Biology (CSIR-CCMB), Hyderabad, India. ${ }^{65}$ Department of Medicine and 
medRxiv preprint doi: https://doi.org/10.1101/2020.09.22.20198937; this version posted September 23, 2020. The copyright holder for this preprint (which was not certified by peer review) is the author/funder, who has granted medRxiv a license to display the preprint in

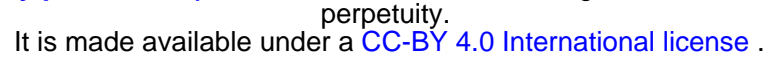

Therapeutics, The Chinese University of Hong Kong, Hong Kong, China. ${ }^{66}$ Chinese University of Hong KongShanghai Jiao Tong University Joint Research Centre in Diabetes Genomics and Precision Medicine, The Chinese University of Hong Kong, Hong Kong, China. ${ }^{67}$ Division of Endocrinology, Metabolism, and Molecular Medicine, Department of Medicine, Northwestern University Feinberg School of Medicine, Chicago, IL, USA. ${ }^{68}$ Department of Health and Biomedical Informatics, Northwestern University Feinberg School of Medicine, Chicago, IL, USA. ${ }^{69}$ Institute of Biomedical Sciences, Academia Sinica, Taipei, Taiwan. ${ }^{70} \mathrm{CNRS-UMR8199,} \mathrm{Lille}$ Pasteur Institute, Lille University, Lille, France. ${ }^{71}$ Department of Epidemiology, Johns Hopkins University, Baltimore, MD, USA. ${ }^{72}$ Department of Medicine, Johns Hopkins University School of Medicine, Baltimore, MD, USA. ${ }^{73}$ Laboratory of Neurogenetics, National Institute on Aging, National Institutes of Health, Bethesda, MD, USA. ${ }^{74}$ Center for Research on Genomics and Global Health, National Human Genome Institute, National Institutes of Health, Bethesda, MD, USA. ${ }^{75}$ Cardiovascular Health Research Unit, Departments of Medicine, Epidemiology, and Health Services, University of Washington, Seattle, WA, USA. ${ }^{76}$ Laboratory of Epidemiology and Population Sciences, National Institute on Aging, National Institutes of Health, Baltimore, MD, USA.

${ }^{77}$ Division of Statistical Genomics, Washington University School of Medicine, St. Louis, MO, USA. ${ }^{78}$ Department of Research and Evaluation, Division of Biostatistics Research, Kaiser Permanente of Southern California, Pasadena, CA, USA. ${ }^{79}$ Department of Biomedical Science, Hallym University, Chuncheon, South Korea. ${ }^{80}$ Department of Nutrition, Gillings School of Global Public Health, University of North Carolina at Chapel Hill, Chapel Hill, NC, USA. ${ }^{81}$ Unidad de Investigación en Enfermedades Metabólicas and Departamento de Endocrinología y Metabolismo, Instituto Nacional de Ciencias Médicas y Nutrición Salvador Zubirán, Mexico City, Mexico. ${ }^{82}$ Laboratory for Statistical and Translational Genetics, RIKEN Centre for Integrative Medical Sciences, Yokohama, Japan. ${ }^{83}$ Department of Ocular Pathology and Imaging Science, Graduate School of Medical Sciences, Kyushu University, Fukuoka, Japan. ${ }^{84}$ Department of Health Research Methods, Evidence, and Impact, McMaster University, Hamilton, ON, Canada. ${ }^{85}$ Department of Epidemiology and Prevention, Division of Public Health Sciences, Wake Forest School of Medicine, Winston-Salem, NC, USA. ${ }^{86}$ Chinese Academy of Medical Sciences, Beijing, China. ${ }^{87}$ Institute of Regional Health Research, University of Southern Denmark, Odense, Denmark. ${ }^{88}$ Department of Clinical Biochemistry, Vejle Hospital, Vejle, Denmark. ${ }^{89}$ Department of Anesthesiology, University of Michigan Medical School, Ann Arbor, MI, USA. ${ }^{90}$ Department of Medicine, Division of Endocrinology and Diabetes, Keck School of Medicine of USC, Los Angeles, CA, USA. ${ }^{91}$ Hong Kong Institute of Diabetes and Obesity, The Chinese University of Hong Kong, Hong Kong, China. ${ }^{92} \mathrm{Li}$ Ka Shing Institute of Health Sciences, The Chinese University of Hong Kong, Hong Kong, China. ${ }^{93}$ Singapore Eye Research Institute, Singapore National Eye Centre, Singapore, Singapore. ${ }^{94}$ Wellcome Sanger Institute, Hinxton, UK. ${ }^{95}$ Department of Biostatistical Sciences, Division of Public Health Sciences, Wake Forest University Health Sciences, Winston-Salem, NC, USA. ${ }^{96}$ Medical Research Council Population Health Research Unit, University of Oxford, Oxford, UK. ${ }^{97}$ Division of Endocrinology and Metabolism, Department of Internal Medicine, National Taiwan University Hospital, Taipei, Taiwan. ${ }^{98}$ Institute of Preventive Medicine, School of Public Health, National Taiwan University, Taipei, Taiwan. ${ }^{99}$ Department of Medicine, University of Vermont, Colchester, VT, USA. ${ }^{100}$ Section on Endocrinology and Metabolism, Department of Internal Medicine, Wake Forest School of Medicine, Winston-Salem, NC, USA. ${ }^{101}$ Department of Medicine, Faculty of Medicine, University of Kelaniya, Ragama, Sri Lanka. ${ }^{102}$ Department of Nutrition and Dietetics, Harokopio University of Athens, Athens, Greece. ${ }^{103}$ Department of Nephrology and Medical Intensive Care Medicine, Charité Universitätsmedizin Berlin, Berlin, Germany. ${ }^{104}$ Department of Nephrology and Hypertension, Friedrich-Alexander-Universität ErlangenNürnberg, Erlangen, Germany. ${ }^{105}$ Department of Biostatistics, University of Washington, Seattle, WA, USA. ${ }^{106}$ California Pacific Medical Center Research Institute, San Francisco, CA, USA. ${ }^{107}$ Robertson Centre for Biostatistics, University of Glasgow, Glasgow, UK. ${ }^{108 I}$ nstitute of Molecular Medicine, University of Texas Health Science Center at Houston, Houston, TX, USA. ${ }^{109}$ Genetics of Complex Traits, University of Exeter Medical School, University of Exeter, Exeter, UK. ${ }^{110}$ Department of Internal Medicine, Wake Forest School of Medicine, Winston-Salem, NC, USA. ${ }^{111}$ Institute for Biomedicine, Eurac Research, Affiliated Institute of the University of Lübeck, Bolzano, Italy. ${ }^{112}$ Department of Medicine, Division of Endocrinology and Metabolism, Lundquist Research Institute at Harbor-UCLA Medical Center, Torrance, CA, USA. ${ }^{113}$ Department of Public Health and Caring Sciences, Uppsala University, Uppsala, Sweden. ${ }^{114}$ Centro de Estudios en Diabetes, Unidad de Investigacion en Diabetes y Riesgo Cardiovascular, Centro de Investigacion en Salud Poblacional, Instituto Nacional de Salud Publica, Mexico City, Mexico. ${ }^{115}$ Department of Medicine, Division of Endocrinology, Diabetes and Metabolism, Cedars-Sinai Medical Center, Los Angeles, CA, USA. ${ }^{116}$ Centre for Epigenomics, University of California San Diego, La Jolla, CA, USA. ${ }^{117}$ Department of Laboratory Medicine and Pathology, University of Minnesota, Minneapolis, MN, USA. ${ }^{118}$ University of Exeter Medical School, University of Exeter, Exeter, UK. ${ }^{119}$ Institute for Clinical Diabetology, German Diabetes Center, Leibniz Center for Diabetes Research at Heinrich Heine University Düsseldorf, Düsseldorf, Germany. ${ }^{120}$ Division of Endocrinology and Diabetology, 
medRxiv preprint doi: https://doi.org/10.1101/2020.09.22.20198937; this version posted September 23, 2020. The copyright holder for this preprint (which was not certified by peer review) is the author/funder, who has granted medRxiv a license to display the preprint in perpetuity.

It is made available under a CC-BY 4.0 International license .

Medical Faculty, Heinrich Heine University Düsseldorf, Düsseldorf, Germany. ${ }^{121}$ Department of Biostatistics, Carolina Population Center, Gillings School of Global Public Health, University of North Carolina at Chapel Hill, Chapel Hill, NC, USA. ${ }^{122}$ Department of Internal Medicine, Diabetes and Metabolism Research Center, Ohio State University Wexner Medical Center, Columbus, OH, USA. ${ }^{123}$ Center for Global Cardiometabolic Health, Brown University, Providence, RI, USA. ${ }^{124}$ Department of Genetics, Shanghai-MOST Key Laboratory of Health and Disease Genomics, Chinese National Human Genome Center at Shanghai, Shanghai, China. ${ }^{125}$ Division of Endocrine and Metabolism, Tri-Service General Hospital Songshan Branch, Taipei, Taiwan. ${ }^{126}$ School of Medicine, National Defense Medical Center, Taipei, Taiwan. ${ }^{127}$ Section of Endocrinology and Metabolism, Department of Medicine, Taipei Veterans General Hospital, Taipei, Taiwan. ${ }^{128}$ School of Medicine, National Yang-Ming University, Taipei, Taiwan. ${ }^{129}$ Department of Environmental and Preventive Medicine, Jichi Medical University School of Medicine, Shimotsuke, Japan. ${ }^{130}$ University of Chicago Research Bangladesh, Dhaka, Bangladesh. ${ }^{131}$ Department of Ophthalmology, Medical Faculty Mannheim of the University of Heidelberg, Mannheim, Germany. ${ }^{132}$ Steno Diabetes Center Copenhagen, Gentofte, Denmark. ${ }^{133}$ National Institute of Public Health, Southern Denmark University, Copenhagen, Denmark. ${ }^{134}$ Center for Clinical Research and Prevention, Bispebjerg and Frederiksberg Hospital, Frederiksberg, Denmark. ${ }^{135}$ Faculty of Health and Medical Sciences, University of Copenhagen, Copenhagen, Denmark. ${ }^{136}$ Faculty of Medicine, Aalborg University, Aalborg, Denmark. ${ }^{137}$ Laboratory of Complex Trait Genomics, Department of Computational Biology and Medical Sciences, Graduate School of Frontier Sciences, The University of Tokyo, Tokyo, Japan. ${ }^{138}$ Department of Clinical Diabetes, Endocrinology \& Metabolism, Department of Translational Research and Cellular Therapeutics, City of Hope, Duarte, CA, USA. ${ }^{139}$ Department of Public Health, Faculty of Medicine, University of Kelaniya, Ragama, Sri Lanka. ${ }^{140}$ Department of Clinical Gene Therapy, Osaka University Graduate School of Medicine, Osaka, Japan. ${ }^{141}$ Department of Geriatric and General Medicine, Graduate School of Medicine, Osaka University, Osaka, Japan. ${ }^{142}$ Division of General Internal Medicine and Geriatrics, Department of Medicine, Northwestern University Feinberg School of Medicine, Chicago, IL, USA. ${ }^{143}$ Center for Health Information Partnerships, Institute for Public Health and Medicine, Northwestern University Feinberg School of Medicine, Chicago, IL, USA. ${ }^{144}$ Genome Institute of Singapore, Agency for Science, Technology and Research, Singapore, Singapore. ${ }^{145}$ Department of Biochemistry, National University of Singapore, Singapore, Singapore. ${ }^{146}$ Department of Molecular Cell Biology, Sungkyunkwan University School of Medicine, Suwon, South Korea. ${ }^{147}$ Department of Regional Resource Management, Ehime University Faculty of Collaborative Regional Innovation, Ehime, Japan. ${ }^{148}$ Institute of Genetic Epidemiology, Department of Genetics and Pharmacology, Medical University of Innsbruck, Innsbruck, Austria. ${ }^{149}$ Institute of Clinical Medicine, Internal Medicine, University of Eastern Finland and Kuopio University Hospital, Kuopio, Finland. ${ }^{150}$ Institute of Mathematics and Statistics, University of Tartu, Tartu, Estonia. ${ }^{151}$ Department of Medicine, University of Colorado Denver, Anschutz Medical Campus, Aurora, CO, USA. ${ }^{152}$ Severance Biomedical Science Institute and Department of Internal Medicine, Yonsei University College of Medicine, Seoul, South Korea. ${ }^{153}$ Department of Medicine, Samsung Medical Center, Sungkyunkwan University School of Medicine, Seoul, South Korea. ${ }^{154}$ Department of Anthropology, Sociology and History, University of San Carlos, Cebu City, Philippines. ${ }^{155}$ Department of Medicine, Harvard Medical School, Boston, MA, USA. ${ }^{156}$ Division of General Internal Medicine, Massachusetts General Hospital, Boston, MA, USA. ${ }^{157}$ Departments of Epidemiology and Biostatistics, Peking University Health Science Centre, Peking University, Beijing, China. ${ }^{158}$ Department of Clinical Epidemiology, Leiden University Medical Center, Leiden, The Netherlands. ${ }^{159}$ Program in Medical \& Population Genetics, Broad Institute, Cambridge, MA, USA. ${ }^{160} \mathrm{Big}$ Data Institute, Li Ka Shing Centre for Health Information and Discovery, University of Oxford, Oxford, UK. ${ }^{161}$ Department of Clinical Medicine, Faculty of Health and Medical Sciences, University of Copenhagen, Copenhagen, Denmark. ${ }^{162}$ Department of Medicine, Yong Loo Lin School of Medicine, National University of Singapore and National University Health System, Singapore, Singapore. ${ }^{163}$ McDonnell Genome Institute, Washington University School of Medicine, St. Louis, MO, USA. ${ }^{164}$ Department of Medicine, Division of Genomics and Bioinformatics, Washington University School of Medicine, St. Louis, MO, USA. ${ }^{165}$ Department of Biostatistics and Data Science, University of Texas Health Science Center at Houston, Houston, TX, USA. ${ }^{166}$ Department of Clinical Sciences, Diabetes and Endocrinology, Lund University Diabetes Centre, Malmö, Sweden. ${ }^{167}$ Department of Clinical Science, KG Jebsen Center for Diabetes Research, University of Bergen, Bergen, Norway. ${ }^{168}$ Dromokaiteio Psychiatric Hospital, National and Kapodistrian University of Athens, Athens, Greece. ${ }^{169}$ Institute of Human Genetics, Helmholtz Zentrum München, German Research Center for Environmental Health, Neuherberg, Germany. ${ }^{170}$ Institute of Human Genetics, Technical University of Munich, Munich, Germany. ${ }^{171}$ German Centre for Cardiovascular Research (DZHK), Partner Site Munich Heart Alliance, Munich, Germany. ${ }^{172}$ The Usher Institute to the Population Health Sciences and Informatics, University of Edinburgh, Edinburgh, UK. ${ }^{173}$ Digital Health Center, Digital Engineering Faculty of Hasso Plattner Institue and University Potsdam, Potsdam, Germany. ${ }^{174}$ Department of Medicine and Pharmacology, New York Medical 
medRxiv preprint doi: https://doi.org/10.1101/2020.09.22.20198937; this version posted September 23, 2020. The copyright holder for this preprint (which was not certified by peer review) is the author/funder, who has granted medRxiv a license to display the preprint in perpetuity.

It is made available under a CC-BY 4.0 International license.

College, Valhalla, NY, USA. ${ }^{175}$ Data Tecnica International LLC, Geln Echo, MD, USA. ${ }^{176}$ Kelly Services, Rockville, MD, USA. ${ }^{177}$ William Harvey Research Institute, Barts and The London School of Medicine and Dentistry, Queen Mary University of London, London, UK. ${ }^{178}$ Department of Statistical Genetics, Osaka University Graduate School of Medicine, Osaka, Japan. ${ }^{179}$ Laboratory of Statistical Immunology, Immunology Frontier Research Center (WPI-IFReC), Osaka University, Osaka, Japan. ${ }^{180}$ Instituto Nacional de Medicina Genómica, Mexico City, Mexico. ${ }^{181}$ Division of Pulmonary, Allergy, and Critical Care Medicine, Department of Medicine, University of Pittsburgh, Pittsburgh, PA, USA. ${ }^{182}$ Division of Epidemiology and Community Health, School of Public Health, University of Minnesota, Minneapolis, MN, USA. ${ }^{183}$ Department of Diabetes and Endocrinology, Nelson R Mandela School of Medicine, College of Health Sciences, University of KwaZulu-Natal, Durban, South Africa. ${ }^{184}$ Academy of Scientific and Innovative Research, CSIR-Institute of Genomics and Integrative Biology, New Delhi, India. ${ }^{185}$ Genomics and Molecular Medicine Unit, CSIR-Institute of Genomics and Integrative Biology, New Delhi, India. ${ }^{186}$ Department of Preventive Medicine, Northwestern University Feinberg School of Medicine, Chicago, IL, USA. ${ }^{187}$ Fred Hutchinson Cancer Research Center, Seattle, WA, USA. ${ }^{188}$ Ophthalmology and Visual Sciences Academic Clinical Program (Eye ACP), Duke-NUS Medical School, Singapore, Singapore. ${ }^{189}$ Department of Ophthalmology, Yong Loo Lin School of Medicine, National University of Singapore and National University Health System, Singapore, Singapore. ${ }^{190}$ Department of Pediatrics, Pediatric Diabetes Research Center, University of California San Diego, La Jolla, CA, USA. ${ }^{191}$ Institute for Genomic Medicine, University of California San Diego, La Jolla, CA, USA. ${ }^{192}$ Department of Cellular and Molecular Medicine, University of California San Diego, La Jolla, CA, USA. ${ }^{193}$ Institute of Cardiovascular and Medical Sciences, University of Glasgow, Glasgow, UK. ${ }^{194}$ Hasso Plattner Institute for Digital Health at Mount Sinai, Icahn School of Medicine at Mount Sinai, New York, NY, USA. ${ }^{195}$ Survey Research Center, Institute for Social Research, University of Michigan, Ann Arbor, MI, USA. ${ }^{196}$ Institute of Genetic Epidemiology, Helmholtz Zentrum Munchen, German Research Center for Environmental Health, Neuherberg, Germany. ${ }^{197}$ Institute for Medical Informatics Biometry and Epidemiology, Ludwig-Maximilians University, Munich, Germany. ${ }^{198}$ Department of Diabetes and Metabolic Diseases, Graduate School of Medicine, The University of Tokyo, Tokyo, Japan.

${ }^{199}$ Department of Genomic Medicine, National Cerebral and Cardiovascular Center, Osaka, Japan. ${ }^{200}$ Faculty of Medicine, University of Reykjavik, Reykjavik, Iceland. ${ }^{201}$ Faculty of Medicine, Macau University of Science and Technology, Macau, China. ${ }^{202}$ Department of Medical Genetics and Medical Research, China Medical University Hospital, Taichung, Taiwan. ${ }^{203}$ Department of Health, National Institute for Health and Welfare, Helsinki, Finland. ${ }^{204}$ National School of Public Health, Madrid, Spain. ${ }^{205}$ Department of Neuroscience and Preventive Medicine, Danube-University Krems, Krems, Austria. ${ }^{206}$ Diabetes Research Group, King Abdulaziz University, Jeddah, Saudi Arabia. ${ }^{207}$ Unidad de Biología Molecular y Medicina Genómica, Instituto Nacional de Ciencias Médicas y Nutrición Salvador Zubirán, Mexico City, Mexico. ${ }^{208}$ Departamento de Medicina Genómica y Toxiología Ambiental, Instituto de Investigaciones Biomédicas, UNAM, Mexico City, Mexico. ${ }^{209}$ Unidad de Investigacion Medica en Bioquimica, Hospital de Especialidades, Centro Medico Nacional Siglo XXI, IMSS, Mexico City, Mexico. ${ }^{210}$ Department of Nutrition, Harvard T.H. Chan School of Public Health, Boston, MA, USA. ${ }^{211}$ Einthoven Laboratory for Experimental Vascular Medicine, Leiden University Medical Center, Leiden, The Netherlands. ${ }^{212}$ Department of Human Genetics, Leiden University Medical Center, Leiden, The Netherlands. ${ }^{213}$ Department of Clinical Chemistry, Laboratory of Genetic Metabolic Disease, Amsterdam University Medical Center, Amsterdam, The Netherlands. ${ }^{214}$ Ophthalmology, Southern California Eye Institute, CHA Hollywood Presbyterian Hospital, Los Angeles, CA, USA. ${ }^{215}$ Department of Medicine, University of Pennsylvania Perelman School of Medicine, Philadelphia, PA, USA. ${ }^{216}$ Unidad de Investigación Médica en Epidemiologia Clinica, Hospital de Especialidades, Centro Medico Nacional Siglo XXI, IMSS, Mexico City, Mexico. ${ }^{217}$ Department of Medicine, School of Medicine, University of North Carolina at Chapel Hill, Chapel Hill, NC, USA. ${ }^{218}$ Department of Internal Medicine, Division of Endocrinology, Leiden University Medical Center, Leiden, The Netherlands. ${ }^{219}$ Department of Public Health, Aarhus University, Aarhus, Denmark. ${ }^{220}$ Danish Diabetes Academy, Odense, Denmark. ${ }^{221}$ Diabetology Research Centre, King Edward Memorial Hospital and Research Centre, Pune, India. ${ }^{222}$ Department of Medical Biochemistry, Kurume University School of Medicine, Kurume, Japan. ${ }^{223}$ Institute for Molecular Bioscience, University of Queensland, Brisbane, Australia. ${ }^{224}$ Division of Cancer Control and Population Sciences, UPMC Hillman Cancer Center, University of Pittsburgh, Pittsburgh, PA, USA. ${ }^{225}$ Department of Epidemiology, Graduate School of Public Health, University of Pittsburgh, Pittsburgh, PA, USA. ${ }^{226}$ Department of Pediatrics, Division of Genetic and Genomic Medicine, UCI Irvine School of Medicine, Irvine, CA, USA. ${ }^{227}$ Department of Anti-aging Medicine, Ehime University Graduate School of Medicine, Ehime, Japan. ${ }^{228}$ Division of Pulmonary, Critical Care, and Sleep Medicine, Beth Israel Deaconess Medical Center, Boston, MA, USA. ${ }^{229}$ Department of Medical Sciences, Uppsala University, Uppsala, Sweden. ${ }^{230}$ Human Genetics Center, University of Texas Health Science Center at Houston, Houston, TX, USA. ${ }^{231}$ Department of Medicine, Division of Cardiovascular Medicine, Stanford University School of Medicine, Stanford, CA, USA. 
medRxiv preprint doi: https://doi.org/10.1101/2020.09.22.20198937; this version posted September 23, 2020. The copyright holder for this preprint (which was not certified by peer review) is the author/funder, who has granted medRxiv a license to display the preprint in perpetuity.

It is made available under a CC-BY 4.0 International license.

${ }^{232}$ Department of Medical Sciences, Molecular Epidemiology and Science for Life Laboratory, Uppsala University, Uppsala, Sweden. ${ }^{233}$ Kaiser Permanente Washington Research Institute, Seattle, WA, USA. ${ }^{234}$ Beijing Institute of Ophthalmology, Ophthalmology and Visual Sciences Key Laboratory, Beijing Tongren Hospital, Capital Medical University, Beijing, China. ${ }^{235}$ Department of Medicine, Division of Cardiology, Duke University School of Medicine, Durham, NC, USA. ${ }^{236}$ TUM School of Medicine, Technical University of Munich and Klinikum Rechts der Isar, Munich, Germany. ${ }^{237}$ Kurume University School of Medicine, Kurume, Japan. ${ }^{238}$ Center for Public Health Genomics, University of Virginia School of Medicine, Charlottesville, VA, USA. ${ }^{239}$ Department of Medicine, McGill University, Montreal, QC, Canada. ${ }^{240}$ Department of Human Genetics, McGill University, Montreal, QC, Canada. ${ }^{241}$ Department of Genomics of Common Disease, School of Public Health, Imperial College London, London, UK. ${ }^{242}$ Department of Physiology and Biophysics, University of Mississippi Medical Center, Jackson, MS, USA. ${ }^{243}$ Division of Endocrinology and Metabolism, Department of Medicine, Taichung Veterans General Hospital, Taichung, Taiwan. ${ }^{244}$ Center for Genetic Medicine, Northwestern University Feinberg School of Medicine, Chicago, IL, USA. ${ }^{245}$ Department of Anthropology, Northwestern University, Evanston, IL, USA. ${ }^{246}$ Genome Technology Branch, National Human Genome Research Institute, National Institutes of Health, Bethesda, MD, USA. ${ }^{247}$ Systems Genomics Laboratory, School of Biotechnology, Jawaharlal Nehru University, New Delhi, India. ${ }^{248}$ Department of Pathology and Molecular Medicine, McMaster University, Hamilton, ON, Canada. ${ }^{249}$ Department of Internal Medicine, Seoul National University College of Medicine, Seoul, South Korea. ${ }^{250}$ Department of Molecular Medicine and Biopharmaceutical Sciences, Graduate School of Convergence Science and Technology, Seoul National University, Seoul, South Korea. ${ }^{251}$ Clinical Cooperation Group Type 2 Diabetes, Helmholtz Zentrum München, Ludwig-Maximilians University, Munich, Germany. ${ }^{252}$ Clinical Cooperation Group Nutrigenomics and Type 2 Diabetes, Helmholtz Zentrum München, Technical University of Munich, Munich, Germany. ${ }^{253}$ MRC-PHE Centre for Environment and Health, Imperial College London, London, UK. ${ }^{254}$ Duke-NUS Medical School, Singapore, Singapore. ${ }^{255} \mathrm{Health}$ Services and Systems Research, Duke-NUS Medical School, Singapore, Singapore. ${ }^{256} \mathrm{Pat}$ Macpherson Centre for Pharmacogenetics and Pharmacogenomics, University of Dundee, Dundee, UK. ${ }^{257}$ Department of Medicine, Brown University Alpert School of Medicine, Providence, RI, USA. ${ }^{258}$ Imperial College Healthcare NHS Trust, Imperial College London, London, UK. ${ }^{259}$ National Heart and Lung Institute, Imperial College London, London, UK. ${ }^{260}$ The Mindich Child Health and Development Institute, Ichan School of Medicine at Mount Sinai, New York, NY, USA. ${ }^{261}$ Department of Biostatistics and Epidemiology, University of Pennsylvania, Philadelphia, PA, USA. ${ }^{262}$ Center for Non-Communicable Diseases, Karachi, Pakistan. ${ }^{263}$ Department of Advanced Genomic and Laboratory Medicine, Graduate School of Medicine, University of the Ryukyus, Okinawa, Japan. ${ }^{264}$ Division of Clinical Laboratory and Blood Transfusion, University of the Ryukyus Hospital, Okinawa, Japan. ${ }^{265}$ Section of Genetics and Genomics, Department of Metabolism, Digestion and Reproduction, Imperial College London, London, UK. ${ }^{266}$ Oxford NIHR Biomedical Research Centre, Churchill Hosptial, Oxford University Hospitals NHS Foundation Trust, Oxford, UK. ${ }^{267}$ Division of Endocrinology, Department of Pediatrics, Stanford School of Medicine, Stanford University, Stanford, CA, USA. ${ }^{268}$ Center for Diabetes Research, Wake Forest School of Medicine, Winston-Salem, NC, USA. ${ }^{269}$ Centre for Genetics and Genomics Versus Arthritis, Centre for Musculoskeletal Research, Division of Musculoskeletal and Dermatological Sciences, University of Manchester, Manchester, UK. ${ }^{270}$ Present address: Genentech, 1 DNA Way, South San Francisco, CA, USA. ${ }^{271}$ Contributors are reported in Supplementary Note 3. ${ }^{*}$ These authors contributed equally to this work. ${ }^{\dagger}$ These authors supervised this work. ${ }^{\ddagger} e-m a i l:$ mahajan.anubha@gene.com; mccarthy.mark@gene.com; andrew.morris-5@manchester.ac.uk. 
medRxiv preprint doi: https://doi.org/10.1101/2020.09.22.20198937; this version posted September 23, 2020. The copyright holder for this preprint (which was not certified by peer review) is the author/funder, who has granted medRxiv a license to display the preprint in

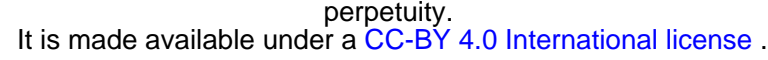

\section{ABSTRACT}

We assembled an ancestrally diverse collection of genome-wide association studies of type 2 diabetes (T2D) in 180,834 cases and 1,159,055 controls (48.9\% non-European descent). We identified 277 loci at genome-wide significance $\left(p<5 \times 10^{-8}\right)$, including 237 attaining a more stringent trans-ancestry threshold $\left(p<5 \times 10^{-9}\right)$, which were delineated to 338 distinct association signals. Trans-ancestry meta-regression offered substantial enhancements to fine-mapping, with $58.6 \%$ of associations more precisely localised due to population diversity, and $54.4 \%$ of signals resolved to a single variant with $>50 \%$ posterior probability. This improved fine-mapping enabled systematic assessment of candidate causal genes and molecular mechanisms through which T2D associations are mediated, laying foundations for functional investigations. Trans-ancestry genetic risk scores enhanced transferability across diverse populations, providing a step towards more effective clinical translation to improve global health. 
medRxiv preprint doi: https://doi.org/10.1101/2020.09.22.20198937; this version posted September 23, 2020. The copyright holder for this preprint (which was not certified by peer review) is the author/funder, who has granted medRxiv a license to display the preprint in

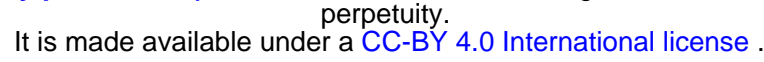

\section{MAIN TEXT}

Type 2 diabetes (T2D) is increasing in prevalence worldwide and contributes substantially to the global burden of mortality and disability. Genome-wide association studies (GWAS) have been extremely successful in identifying T2D susceptibility loci but have mostly focused on populations of European ancestry (1-4). To address this population bias, more recent largescale T2D GWAS have expanded into East Asian ancestry populations $(5,6)$ and multiancestry biobanks $(7,8)$. The DIAMANTE (DIAbetes Meta-ANalysis of Trans-Ethnic association studies) Consortium was established to assemble T2D GWAS across diverse populations and develop methodological blueprints for intra- and inter-ancestry meta-analyses relevant to any complex trait. Analyses of the European and East Asian ancestry-specific components of DIAMANTE have previously been reported $(4,6)$. Here, we describe the results of our transancestry meta-analysis of T2D GWAS, which partially overlaps with these ancestry-specific efforts, focussing on genetic variation shared across population groups at loci robustly associated with the disease. With these data, we demonstrate the value of analyses conducted in diverse populations to understand how T2D-associated variants impact downstream molecular and biological processes underlying the disease, and to advance clinical translation for all, irrespective of ancestry.

Robust discovery of trans-ancestry T2D associations. We accumulated summary statistics from 122 GWAS with a total of 180,834 T2D cases and 1,159,055 controls (effective sample size 492,191) from five ancestry groups (Figure S1, Tables S1 and S2): European (51.1\%); East Asian (28.4\%); South Asian (8.3\%); African (6.6\%); and Hispanic/Latino (5.6\%). Here, we use the term "ancestry group" to refer to populations with similar genetic ancestry and/or admixture profiles. We imputed each GWAS to reference panels from the 1000 Genomes Project $(9,10)$, Haplotype Reference Consortium (11), or population-specific whole-genome sequence data (Supplementary Materials and Methods, Table S3). We considered $19,829,461$ bi-allelic autosomal single nucleotide variants (SNVs) that overlapped the reference panels and had minor allele frequency (MAF) $>0.5 \%$ in at least one of the five ancestry groups (Supplementary Materials and Methods).

The most powerful methods for discovery of novel loci through trans-ancestry metaanalysis allow for potential allelic effect heterogeneity between ancestry groups that cannot be accommodated in a fixed-effects model (12). In contrast, random-effects meta-analysis does not assume any structure to heterogeneity across GWAS. To address these limitations, our primary analysis used MR-MEGA (13), a meta-regression approach that models allelic effect heterogeneity correlated with ancestry by including axes of genetic variation as covariates to represent diversity between GWAS (Supplementary Materials and Methods). We considered three axes of genetic variation that separated GWAS from the five ancestry groups, and which also revealed finer-scale genetic differences between GWAS of similar ancestry (Figure S2). In particular, the second axis highlights the extent of African and European admixture amongst African American GWAS, whilst the third axis differentiates Hispanic/Latino studies with variable proportions of indigenous American and African ancestry.

We identified 277 loci associated with T2D at the traditional genome-wide significance threshold of $p<5 \times 10^{-8}$ in the trans-ancestry meta-regression (Figure S3, Table S4). By accounting for ancestry-correlated allelic effect heterogeneity in the trans-ancestry meta-regression, we observed lower genomic control inflation $\left(\lambda_{\mathrm{GC}}=1.05\right)$ than when using 
medRxiv preprint doi: https://doi.org/10.1101/2020.09.22.20198937; this version posted September 23, 2020. The copyright holder for this preprint (which was not certified by peer review) is the author/funder, who has granted medRxiv a license to display the preprint in perpetuity.

It is made available under a CC-BY 4.0 International license.

either fixed- or random-effects meta-analysis ( $\lambda_{G C}=1.25$ under both models). Consequently, after genomic control correction, we observed stronger signals of association at lead SNVs at most loci in the meta-regression than in the fixed-or random-effects meta-analyses (Figure S4). Eleven of the 277 loci have not been reported in recently published T2D GWAS meta-analyses $(4,6,8)$, which together contributed $78.6 \%$ of the total effective sample size of this trans-ancestry meta-regression (Figure S3). Supplementary Note 1 summarises the loci reported across investigations incorporating DIAMANTE GWAS.

To gain insight into the power offered by aggregating GWAS from diverse populations, we sought to compare the number of loci identified in trans-ancestry metaregression and ancestry-specific meta-analyses. There are minor differences in the GWAS contributing to the trans-ancestry meta-regression and the previously reported European and East Asian ancestry-specific components of DIAMANTE $(4,6)$. To make a direct comparison of locus discovery, we therefore undertook ancestry-specific fixed-effects metaanalyses of only those GWAS contributing to the trans-ancestry meta-regression (Supplementary Materials and Methods). Of the 100 and 193 loci attaining genome-wide significance in the East Asian and European ancestry-specific meta-analyses, respectively, lead SNVs at 94 (94.0\%) and 164 (85.0\%) demonstrated stronger evidence for association in the trans-ancestry meta-regression (Figure S5). In contrast, eleven (5.7\%) of the 193 loci identified in the European ancestry-specific meta-analysis did not attain genome-wide significance in the trans-ancestry meta-regression (Table S5). The lead SNVs at these loci demonstrated no significant differences in allelic effect sizes across European ancestry GWAS (Cochran's $Q p<0.0045$, Bonferroni correction), which would suggest that these signals are not false positive associations. None of these SNVs demonstrated significant evidence of T2D association in a meta-analysis of non-European ancestry GWAS, indicating that they could represent European ancestry-specific loci. Such signals could arise when the lead SNV is in strong linkage disequilibrium (LD) with an ancestry-specific causal variant that has not been interrogated in the trans-ancestry meta-regression. Taken together, these results demonstrate the power of diverse populations for locus discovery and replication, but also emphasize the importance of single-ancestry GWAS for optimal identification of ancestry-specific associations.

The traditional genome-wide significance threshold of $p<5 \times 10^{-8}$ was derived from a Bonferroni correction for the equivalent of approximately one million independent, common SNVs in European ancestry populations. However, in a trans-ancestry metaanalysis, the correlation in association summary statistics between SNVs will be weaker because of the different patterns of LD across diverse populations. We therefore derived a more stringent trans-ancestry genome-wide significance threshold of $p<5 \times 10^{-9}$ by estimating the effective number of independent SNVs across ancestries using haplotypes from the 1000 Genomes Project reference panel (10) (Supplementary Materials and Methods). Of the 277 loci reported in this trans-ancestry meta-regression, 237 attained the more stringent significance threshold, including the novel associations mapping to/near PXK, PPP3CA, MYO3A and FOLH1. We focussed only on these 237 loci for the downstream analyses presented here.

Through approximate conditional analyses, conducted using ancestry-matched LD reference panels for each GWAS, we partitioned associations at the 237 T2D loci into 338 distinct signals that were each represented by an index SNV at trans-ancestry genome-wide significance (Supplementary Materials and Methods, Tables S6 and S7). We observed multiple distinct association signals at 52 (21.9\%) loci, of which 50 were represented by 
medRxiv preprint doi: https://doi.org/10.1101/2020.09.22.20198937; this version posted September $23,2020$. The copyright holder for this preprint (which was not certified by peer review) is the author/funder, who has granted medRxiv a license to display the preprint in

It is made available under a CC-BY 4.0 International license.

between two and five index SNVs. The most complex genetic architecture was observed across a $1 \mathrm{Mb}$ region flanking the lead SNV at the TCF7L2 locus, where the T2D association was delineated to 16 distinct signals, and a $1.7 \mathrm{Mb}$ imprinted region encompassing the previously reported loci INS-IGF2 and KCNQ1, which was decomposed into 14 distinct signals (Figures S6 and S7).

Extent and source of trans-ancestry allelic-effect heterogeneity. Of the 338 distinct T2D signals, $317(93.8 \%)$ attained at least nominal evidence of association $(p<0.05)$ in two or more ancestry groups (Table S8). The strength of association ( $p$-value) in each ancestry depends on the effective sample size, and the frequency and effect size (odds-ratio, OR) of the risk allele at the index SNV (Figure S8). Trans-ancestry heterogeneity in allelic effects at an association signal can occur for several reasons, including differences in LD with the causal variant and/or interaction with lifestyle factors that vary across diverse populations. An advantage of the MR-MEGA meta-regression model is that heterogeneity can be partitioned into two components. The first captures heterogeneity that is correlated with ancestry (i.e. can be explained by the three axes of genetic variation). The second reflects residual heterogeneity due to differences in study design (for example variable phenotype definition, case-control ascertainment, or covariate adjustments between GWAS). We observed $27(8.0 \%)$ distinct T2D associations with nominal evidence $\left(p_{H E T}<0.05\right)$ of residual heterogeneity compared to that expected by chance (binomial test $p=0.0037$ ). In contrast, there was nominal evidence of ancestry-correlated heterogeneity at 136 (40.2\%) T2D association signals (binomial test $p<2.2 \times 10^{-16}$ ), suggesting that differences in allelic effect sizes between GWAS are more likely due to factors related to ancestry than to study design.

We next sought to investigate whether these ancestry-correlated heterogeneous association signals could be explained by an interaction with obesity, given that the distribution of body mass index (BMI) is shifted to the left in individuals of East Asian ancestry. To do this, we considered the 136 association signals with nominal evidence of ancestry-correlated heterogeneity in allelic effects, and repeated the meta-regression analysis at each index SNV by including the mean BMI of individuals in each study as a covariate in addition to the three axes of genetic variation (Supplementary Materials and Methods, Table S9). The strongest evidence for heterogeneity in allelic effects that was correlated with BMI (after accounting for ancestry) was observed for the T2D association signals at the CDKAL1 locus ( $\mathrm{rs} 9348441, p_{\mathrm{HET}}=3.0 \times 10^{-6}$ ). At this signal, the effect of the risk allele on T2D was greatest in East Asian ancestry populations, and there was a negative correlation between BMI and log-OR across GWAS (Figure S9). This relationship is consistent with the notion of "favourable adiposity", where BMI increasing alleles are associated with lower insulin levels and higher subcutaneous-to-visceral adipose tissue ratio, which may protect against T2D via higher adipose storage capacity (14). A potential protective interaction with obesity at this locus is supported by: (i) evidence of a stronger association at the index SNV after adjustment for BMI in the European and East Asian ancestry-specific components of DIAMANTE $(4,6)$; and (ii) the T2D-risk allele is significantly associated with decreased BMI in European and East Asian ancestry GWAS meta-analyses of obesity in the general population $(15,16)$.

Population diversity improves fine-mapping resolution. The value of exploiting differences in LD structure between ancestry groups to enhance the localisation of causal variants has been demonstrated in previous T2D GWAS meta-analyses $(17,18)$. We sought to quantify 
medRxiv preprint doi: https://doi.org/10.1101/2020.09.22.20198937; this version posted September 23, 2020. The copyright holder for this preprint (which was not certified by peer review) is the author/funder, who has granted medRxiv a license to display the preprint in

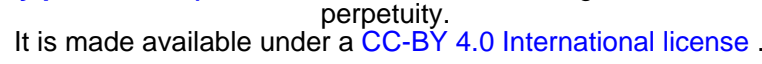

the improvement in fine-mapping resolution offered by increased sample size and population diversity in the trans-ancestry meta-regression over the European ancestryspecific meta-analysis (since the latter represents the largest ancestry-specific component of DIAMANTE). For each of the 338 distinct signals, we derived trans-ancestry and European ancestry-specific credible sets of variants that account for $99 \%$ of the posterior probability $(\pi)$ of driving the T2D association under a uniform prior model of causality (Supplementary Materials and Methods). Trans-ancestry meta-regression substantially reduced the median $99 \%$ credible set size from 35 variants (spanning $112 \mathrm{~kb}$ ) to 10 variants (spanning $26 \mathrm{~kb}$ ), and increased the median posterior probability ascribed to the index SNV from $24.3 \%$ to $42.0 \%$. The 99\% credible sets for 266 (78.7\%) distinct T2D associations were smaller in the transancestry meta-regression than in the European ancestry-specific meta-analysis, whilst a further 26 (7.7\%) signals were resolved to a single SNV in both (Figure 1, Table S10).

Compared to the European ancestry-specific meta-analysis, some of the most dramatic improvements in fine-mapping resolution after trans-ancestry meta-regression included signals where the index SNV was of lower frequency and/or of smaller effect in European ancestry populations. For these signals, including those at GCC1-PAX4-LEP, SGCG, $R G M A, D S T Y K-M D M 4$ and MYO3A, the evidence for association was weak in the European ancestry-specific meta-analysis, resulting in large credible sets compared to other ancestry groups. However, we also observed examples of T2D signals with strong associations across all five ancestry groups for which the credible sets were smaller in the trans-ancestry metaregression, with the most noticeable improvements in fine-mapping resolution observed at TMEM154, HMGA2, GRP-MC4R, IGF2BP2, SPRY2 and FTO (Table S10). At FTO, the 18 variants in the European ancestry-specific $99 \%$ credible set were in strong LD with the index SNV ( $r 555872725$ ) in European ancestry populations $\left(r^{2}>0.8\right)$. However, the $99 \%$ credible set after trans-ancestry meta-regression included just six of these variants that were in strong LD with the index SNV in all five ancestry groups (Figure S10).

We next attempted to understand the relative contributions of population diversity and sample size to these improvements in fine-mapping resolution. We artificially boosted the effective sample size of the European ancestry-specific meta-analysis to that of the trans-ancestry meta-regression by recalibrating standard errors of allelic effect estimates and the genomic control inflation factor (Supplementary Materials and Methods). We considered the 266 distinct T2D associations that were more precisely localised after transancestry meta-regression. Of these, the $99 \%$ credible sets at 156 (58.6\%) signals were better resolved in the trans-ancestry meta-regression (Figure 1, Table S10). At these signals, the addition of non-European ancestry GWAS to the trans-ancestry meta-regression offered greater fine-mapping resolution than equivalent-sized European descent studies. These results highlight the value of diverse populations for causal variant localisation, emphasizing the importance of differences in LD structure and allele frequency distribution between ancestry groups.

Annotation-informed trans-ancestry fine-mapping deconvolutes distinct T2D associations to single variant resolution. Previous T2D GWAS have demonstrated improved localisation of causal variants through integration of fine-mapping data with genomic annotation $(4,19)$. By mapping SNVs to three categories of functional and regulatory annotation, with an emphasis on diabetes-relevant tissues (20), we observed significant joint enrichment $(p<0.00023$, Bonferroni correction for 220 annotations) for T2D associations mapping to protein coding exons, binding sites for NKX2.2, FOXA2, EZH2 and PDX1, and four chromatin 
medRxiv preprint doi: https://doi.org/10.1101/2020.09.22.20198937; this version posted September $23,2020$. The copyright holder for this preprint (which was not certified by peer review) is the author/funder, who has granted medRxiv a license to display the preprint in

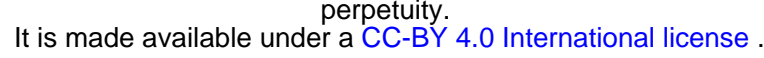

states in pancreatic islets that mark active enhancers, active promoters and transcribed regions (Supplementary Materials and Methods, Table S11, Figure S11). We used the enriched annotations to derive a prior model for causality, and redefined $99 \%$ credible sets of variants for each distinct signal (Supplementary Materials and Methods, Table S12). Annotation-informed fine-mapping reduced the size of the $99 \%$ credible set, compared to the uniform prior, at 144 (42.6\%) distinct association signals (Figure S12), decreasing the median from 10 variants (spanning $26 \mathrm{~kb}$ ) to 8 variants (spanning $23 \mathrm{~kb}$ ). For $98(29.0 \%)$ signals, a single SNV accounted for $>90 \%$ of the posterior probability of the T2D association (Table S13). At a further $86(25.4 \%)$ signals, $>50 \%$ of the posterior probability could be attributed to a single SNV.

\section{Missense variants driving T2D associations implicate candidate causal genes. After} annotation-informed trans-ancestry fine-mapping, 19 of the 184 SNVs accounting for $>50 \%$ of the posterior probability of the T2D association were missense variants (Table S14). These included two that implicate novel candidate causal genes for the disease: $M Y O 5 C$ p.Glu1075Lys ( $r$ 3825801, $p=3.8 \times 10^{-11}, \pi=69.2 \%$ ) at the MYO5C locus; and ACVR1C p.Ile482Val (rs7594480, $p=4.0 \times 10^{-12}, \pi=95.2 \%$ ) at the CYTIP locus. ACVR1C encodes ALK7, a transforming growth factor- $\beta$ receptor, overexpression of which induces growth inhibition and apoptosis of pancreatic $\beta$-cells (21). Three ACVR1C missense variants have been previously associated with body fat distribution (22).

The trans-ancestry meta-regression also highlighted two examples of previously reported T2D coding variant associations that were better resolved by fine-mapping across diverse populations (Figure S13). A set of five coding variants in SLC16A11 has been associated with T2D in populations of Hispanic/Latino ancestry $(23,24)$, but causality could not be ascribed because of strong LD between them. However, after trans-ancestry finemapping, SLC16A11 p.Val113Ile ( $r$ 117767867, $p=6.5 \times 10^{-24}, \pi=59.8 \%$ ) emerged as the variant most likely driving this association signal (the other four coding variants together account for just $14.0 \%$ of the posterior probability). Similarly, strong LD at the KCNJ11$A B C C 8$ locus has frustrated efforts in European ancestry studies to distinguish the impact on T2D of three missense variants: KCNJ11 p.Val250lle (rs5215), KCNJ11 p.Lys23Glu (rs5219) and $A B C C 8$ p.Ala1369Ser (rs757110). ABCC8 and KCNJ11 code for the two elements of the hetero-octameric beta-cell $\mathrm{K}_{\text {ATP }}$ channel and both represent strong biological candidates. Whilst trans-ancestry fine-mapping cannot equivocally distinguish between $K C N J 11$ p.Val250lle ( $\left.p=1.3 \times 10^{-54}, \pi=67.1 \%\right)$ and $K C N J 11$ p.Lys23Glu $\left(p=2.6 \times 10^{-54}, \pi=32.5 \%\right)$, the causal contribution of $A B C C 8$ p.Ala1369Ser $\left(p=1.2 \times 10^{-51}, \pi=0.1 \%\right)$ to this association signal can be discounted.

Trans-ancestry fine-mapping also provided a more detailed view of the role of missense variants in driving three distinct T2D association signals at the ZFAND3-KCNK16GLP1R locus (Figure S14). Previous East Asian ancestry GWAS and exome-array metaanalyses $(5,25)$ reported T2D association with GLP1R p.Arg131GIn (rs3765467). Whilst this variant is included in the $99 \%$ credible set of the signal indexed by rs 742762 , a non-coding SNV, in the trans-ancestry meta-regression, it has a relatively low posterior probability of association ( $\pi=2.0 \%$, compared with $\pi=75.0 \%$ for the index SNV). However, we identified a different GLP1R missense variant, p.Pro7Leu ( $r$ 10305420, $p=1.1 \times 10^{-9}, \pi=94.1 \%$ ), not in LD with $\mathrm{p} . \mathrm{Arg} 131 \mathrm{G}$ n, which seems likely to be causal for the second association signal at the locus. At the third signal, $61.4 \%$ of the posterior probability of association could be attributed to three different missense variants: p.Ser21Gly ( $r$ 10947804, $\pi=39.2 \%$ ) in 
medRxiv preprint doi: https://doi.org/10.1101/2020.09.22.20198937; this version posted September 23, 2020. The copyright holder for this preprint (which was not certified by peer review) is the author/funder, who has granted medRxiv a license to display the preprint in

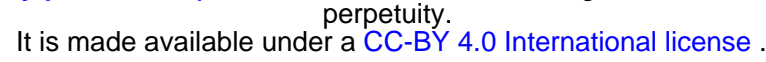

KCNK17; and p.Pro254His ( $r s 11756091, \pi=14.8 \%$ ) and p.Ala277Glu (rs1535500, $\pi=13.7 \%$ ) in KCNK16. Both genes encode members of the TWIK-related alkaline $\mathrm{pH}$-activated K2P family, TALK-1 and TALK-2, and are expressed in islets with high specificity. The missense variants are in strong LD with each other across ancestry groups, and the T2D-risk haplotype is associated with increased $K C N K 17$ expression in pancreatic islets (20). Taken together, these results highlight the complexity of coding variant associations with $T 2 \mathrm{D}$ at this locus, demonstrating a causal role for missense variants encoding GLP1R, KCNK16 and KCNK17 on disease risk.

\section{Multi-omics data integration highlights novel candidate effector genes and causal} mechanisms for non-coding T2D association signals. We next sought to take advantage of the improved fine-mapping resolution offered by the trans-ancestry meta-regression to extend insight into candidate effector genes, tissue specificity and mechanisms through which regulatory variants at non-coding T2D association signals impact disease risk. Here, we describe how data from this study support further characterisation of the regulatory landscape through which T2D association signals are mediated, highlighting examples of two loci, BCAR1 and PROX1, where multi-omics integration builds on our trans-ancestry finemapping to provide novel insights into the pathogenesis of the disease.

We first integrated annotation-informed fine-mapping data with molecular quantitative trait loci (QTL), in cis, for: (i) circulating plasma proteins (pQTL) (26); and (ii) gene expression (eQTL) in diverse tissues, including pancreatic islets, subcutaneous and visceral adipose, liver, skeletal muscle, and hypothalamus $(27,28)$ (Supplementary Materials and Methods). Recognising that molecular QTL may also be driven by multiple causal variants, we dissected distinct plasma PQTL for each protein and distinct eQTL for each gene in each tissue via approximate conditional analyses. Bayesian colocalization (29) of each pair of distinct T2D associations and molecular QTL identified 97 candidate effector genes at 72 signals (posterior probability $\pi_{\text {coloc }}>80 \%$ ): 7 cis-pQTL at 7 signals; and 126 cis-eQTL at 66 signals (Tables S15 and S16). These signals reinforced evidence supporting several genes that have been previously implicated in T2D through extensive functional studies, including ADCY5, STARD10, IRS1, KLF14, SIX3 and TCF7L2 (30-34). A single candidate effector gene was implicated at 49 T2D association signals, of which 10 colocalized with eQTL across multiple tissues: CEP68, ITGB6, RBM6, PCGF3, JAZF1, ANK1, ABO, ARHGAP19, PLEKHA1 and $A P 3 S 2$. In contrast, we observed that cis-eQTL at 44 signals were specific to one tissue (24 to pancreatic islets, 11 to subcutaneous adipose, five to skeletal muscle, two to visceral adipose, and one each to liver and hypothalamus), reiterating the importance of conducting colocalization analyses across multiple tissues.

We then intersected $99 \%$ credible set variants for distinct T2D association signals with genome-wide promoter-focussed chromatin conformation capture data ( $\mathrm{pcHi}-\mathrm{C}$ ) from pancreatic islets, subcutaneous adipose and liver (not available in hypothalamus and visceral adipose) (35-37). Across the three tissues, we observed contacts between credible set variants and putative target gene promoters for 214 (63\%) of the association signals (Table S17). The contacts at 119 of these signals were observed in only one tissue: 51 in islets, 45 in liver, and 23 in subcutaneous adipose. Some targets were expected based on their proximity to the index SNV for the T2D association (including TCF7L2, PROX1, PTEN, DLEU1, GLIS3, CCND2, CMIP and BCL2), but for 143 (67\%) signals, we identified more distant candidate effector genes (including $A Q P 5$ and $A Q P 6$ at the FAIM2 locus, P2RX1 at the ZZEF1 locus, STX16 at the GNAS locus, and ISL1 at the ITGA1 locus). Several of these targets 
medRxiv preprint doi: https://doi.org/10.1101/2020.09.22.20198937; this version posted September 23, 2020. The copyright holder for this preprint (which was not certified by peer review) is the author/funder, who has granted medRxiv a license to display the preprint in

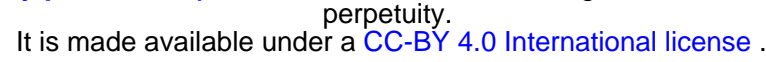

provided complementary support for candidate effector genes identified via colocalization with cis-eQTL in the same tissue: PLEKHA1 in islets and subcutaneous adipose; ST6GAL1, CARD9, DNLZ, CAMK1D, TCF7L2, TH, DLK1 and AP3S2 in islets; DCAF16, STEAP2 and MAN2C1 in subcutaneous adipose; and CEP68 and SLC22A3 in liver.

At the $B C A R 1$ locus, trans-ancestry fine-mapping resolved the T2D association signal to a $99 \%$ credible set of nine variants. These variants overlap a chromatin accessible snATAC-seq peak in human pancreatic acinar cells (38) and an enhancer element in human pancreatic islets which interacts with an islet-accessible, active promoter upstream of the pancreatic exocrine enzyme chymotrypsin B2 gene CTRB2 (36). The observations in bulk pancreatic islets are likely to have arisen due to exocrine (acinar cell) contamination since single cell data does not support its expression in endocrine cells (Figure 2). The T2D association signal also colocalized with a cis-pQTL for circulating plasma levels of chymotrypsin B1 (CTRB1, $\pi_{\text {COLOC }}=98.6 \%$ ). Interestingly, by extending our colocalization analyses at this locus to trans-pQTL, we showed that variants driving the T2D association signal also act to regulate levels of three other pancreatic secretory enzymes produced by the acinar cells that are all involved in the digestion of ingested fats and proteins: carboxypeptidase B1 (CPB1, $\pi_{\text {COLOC }}=98.8 \%$ ), pancreatic lipase related protein 1 (PLRP1, $\pi_{\mathrm{COLOC}}=97.6 \%$ ) and serine protease 2 (PRSS2, $\pi_{\mathrm{COLOC}}=98.3 \%$ ). These observations are consistent with an effect of the T2D-risk alleles on gene and protein expression in the exocrine pancreas, which subsequently influence pancreatic endocrine function. This is in line with a recent study reporting rare mutations in another protein produced by the exocrine pancreas, chymotrypsin-like elastase family member $2 \mathrm{~A}$, which were found to influence levels of digestive enzymes and glucagon, a glucose-raising hormone secreted from the alpha cells in the pancreatic islets (39). Taken together, these complementary findings add to a growing body of evidence linking defects in the exocrine pancreas and T2D pathogenesis $(40,41)$.

At the PROX1 locus, trans-ancestry fine-mapping localised the two distinct association signals to just three variants (Figure 3, Figure S15). The index SNV at the first signal ( $r s 340874, p=1.1 \times 10^{-18}, \pi>99.9 \%$ ) overlaps the $P R O X 1$ promoter in both human liver and pancreatic islets $(20,34)$. At the second signal, the two credible set variants are located in the same enhancer active in islets and liver ( $r$ 79687284, $p=6.9 \times 10^{-19}, \pi=66.7 \%$; rs17712208, $\left.p=1.4 \times 10^{-18}, \pi=33.3 \%\right)$. Recent studies have demonstrated that the T2D-risk allele at rs17712208 (but not rs79687284) results in significant repression of enhancer activity in mouse MIN6 (38) and human EndoC- $\beta \mathrm{H} 1$ beta cell models (42). Furthermore, this enhancer interacts with the PROX1 promoter in islets (36), but not in liver (37). Motivated by these observations, we sought to determine whether these distinct signals impact T2D risk (via $P R O X 1$ ) in a tissue-specific manner by assessing transcriptional activity of the credible set variants (rs340874, rs79687284 and rs17712208) in human HepG2 hepatocytes and EndoC- $\beta \mathrm{H} 1$ beta cell models using in vitro reporter assays (Supplementary Materials and Methods, Figure 3). At the first signal, we demonstrated significant differences in luciferase activity between alleles at rs340874 in both liver $(p=0.0018)$ and islets $(p=0.027)$. However, at the second signal, a significant difference in luciferase activity between alleles

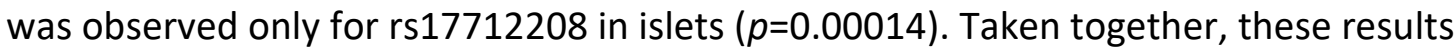
suggest that likely causal variants at these distinct association signals exert their impact on T2D through the same effector gene, PROX1, but act in a tissue-specific manner. 
medRxiv preprint doi: https://doi.org/10.1101/2020.09.22.20198937; this version posted September $23,2020$. The copyright holder for this preprint (which was not certified by peer review) is the author/funder, who has granted medRxiv a license to display the preprint in

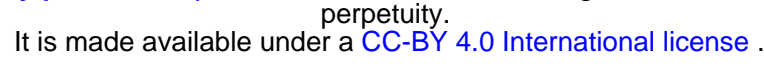

Transferability of T2D genetic risk scores across diverse populations. Genetic risk scores (GRS) derived from European ancestry GWAS have been demonstrated to have limited transferability into other population groups because of ancestry-correlated differences in the frequency and effect of risk alleles (43). We took advantage of the population diversity in DIAMANTE to compare the prediction performance of trans-ancestry and ancestryspecific T2D GRS constructed using lead SNVs at loci attaining genome-wide significance. We hypothesized that the trans-ancestry GRS would perform best for two reasons. First, our analyses have highlighted that the trans-ancestry meta-regression enables discovery of loci associated with disease that are relevant across population groups. Second, we were able to take advantage of the meta-regression framework to estimate population-specific weights for each lead SNV in the GRS by allowing for ancestry-correlated heterogeneity in allelic effects (Supplementary Materials and Methods).

We began by selecting two studies per ancestry group as test GWAS into which the prediction performance of the GRS was assessed using trait variance explained (pseudo $R^{2}$ ) and OR per risk score unit. We repeated the trans-ancestry meta-regression and ancestryspecific meta-analyses, after excluding the test GWAS, and defined lead SNVs at loci attaining genome-wide significance ( $p<5 \times 10^{-9}$ for trans-ancestry GRS and $p<5 \times 10^{-8}$ for ancestry-specific GRS). For each ancestry-specific GRS, we used allelic effect estimates for each lead SNV as weights, irrespective of the population in which the test GWAS was undertaken. However, for the trans-ancestry GRS, we derived weights for each lead SNV that were specific to each test GWAS population. As expected, ancestry-specific GRS performed best into test GWAS from their respective ancestry group, but had relatively weak predictive power into other populations, particularly those of African descent (Figure 4, Table S18). However, the trans-ancestry GRS, weighted with population-specific allelic effect estimates from the meta-regression, showed improved predictive power over ancestry-specific GRS into all test GWAS.

The smallest increase in trait variance explained by the trans-ancestry GRS was observed into European ancestry test GWAS, in line with the substantial contribution of individuals of European descent to the trans-ancestry meta-regression. To further investigate the impact of sample size on prediction performance, we artificially boosted the effective sample size of the European ancestry-specific meta-analysis to that of the transancestry meta-regression (after excluding test GWAS) using the same approach as in our fine-mapping analyses (Supplementary Materials and Methods). Expanding the sample size of the European ancestry-specific meta-analysis increased the number of loci attaining genome-wide significance: these corresponded to weaker association signals that were not discovered with the original sample size. Consequently, the trait variance explained by the European ancestry-specific GRS into test GWAS of European descent was increased with the expanded sample size. However, importantly, despite the increase in sample size, the trait variance explained did not exceed that attained by the trans-ancestry GRS (Figure S16,

Table S19). In contrast, the trait variance explained by the European ancestry-specific GRS into test GWAS from non-European ancestry groups was lower with the expanded sample size than the original sample size. These results suggest that SNVs with weaker association signals in ancestry-specific meta-analyses are less likely to be transferable and thus reduce the predictive power of ancestry-specific GRS into other population groups.

Finally, we tested the predictive power of the trans-ancestry GRS based on all GWAS contributing to DIAMANTE into 18,111 T2D cases and 111,119 controls of Finnish descent from FinnGen (Supplementary Materials and Methods). Using association summary 
medRxiv preprint doi: https://doi.org/10.1101/2020.09.22.20198937; this version posted September $23,2020$. The copyright holder for this preprint (which was not certified by peer review) is the author/funder, who has granted medRxiv a license to display the preprint in

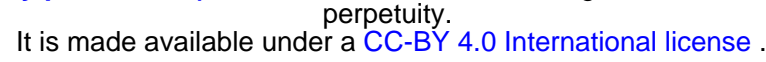

statistics from the meta-regression, we derived Finnish-specific allelic effect estimates to use as weights in the trans-ancestry GRS (Figure S17, Table S20). Individuals in the top decile of the GRS were at 5.34-fold increased risk of T2D compared to those in the bottom decile. The area under the receiver operating characteristic curve (AUC) of a predictive model including the Finnish-specific GRS, in addition to age, sex and BMI, was $83.5 \%$. Each unit of the weighted GRS was associated with 1.24 years earlier age of T2D diagnosis $\left(p=7.1 \times 10^{-57}\right)$, indicating that those with a higher genetic burden are more likely to be affected earlier in life.

Positive selection of T2D risk alleles. Previous investigations (44) have concluded that historical positive selection has not had the major impact on T2D envisaged by the thrifty genotype hypothesis (45). We sought to re-evaluate the evidence for positive selection of T2D risk alleles across our expanded collection of distinct trans-ancestry association signals. We fitted demographic histories to haplotypes for each population in the 1000 Genomes Project reference panel (10) using Relate (46), and quantified the evidence for selection for each T2D index SNV by assessing the extent to which the mutation has more descendants than other lineages that were present when it arose (Supplementary Materials and

Methods). This approach is well powered to detect positive selection acting on polygenic traits over a period of a few thousand to a few ten thousand years. We detected evidence of selection $(p<0.05)$ in four of the five African ancestry populations (but not other ancestry groups) towards increased T2D risk (Figure S18). Given that T2D, itself, is likely to have been an advantageous phenotype only via pleiotropic variants acting through beneficial traits, we tested for association of index SNVs at distinct T2D signals with phenotypes available in the UK Biobank (47) (Supplementary Materials and Methods, Figure S19). We found that T2D risk alleles that were also associated with increased weight (and other obesity-related traits) tended to have more recent origin when compared to the genome-wide mutation age distribution at the same derived allele frequency $(p<0.05$ in all African ancestry populations), consistent with positive selection (Figure S18). Excluding these SNVs removed the selection signature that was observed in African ancestry populations. These observations are consistent with positive selection of T2D risk alleles that has been driven by the promotion of energy storage and usage appropriate to the local environment (48). Further work is needed to characterise the specific pathways responsible for this adaptation.

Discussion. The worldwide prevalence of diabetes mellitus has quadrupled over the last 30 years (49) and was estimated by the International Diabetes Federation to affect 415 million adults in 2015. China and India have emerged as major epicentres of the disease (50), and in the USA, T2D and the downstream complications disproportionately affect individuals from ethnic minorities (51,52). In consideration of the global burden of the disease, the DIAMANTE Consortium has assembled the most ancestrally diverse collection of T2D GWAS to date. To maximise the potential of these valuable resources to understand the genetic contribution to T2D across populations, we have also developed robust protocols for transancestry analyses that will be relevant to any complex human trait. We previously implemented a powerful meta-regression approach (13) to enable aggregation of GWAS summary statistics across diverse populations that allows for heterogeneity in allelic effects on disease risk that is correlated with ancestry. Our study highlighted the advantages of applying this approach to ancestrally diverse GWAS in DIAMANTE for: (i) discovery of 
medRxiv preprint doi: https://doi.org/10.1101/2020.09.22.20198937; this version posted September 23, 2020. The copyright holder for this preprint (which was not certified by peer review) is the author/funder, who has granted medRxiv a license to display the preprint in

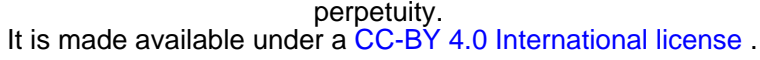

association signals that are shared across populations by reducing the genomic control inflation due to residual stratification; (ii) understanding the extent and source of heterogeneity in allelic effects at distinct association signals; (iii) allowing for LD-driven heterogeneity to improve fine-mapping resolution; and (iv) deriving population-specific weights to improve transferability of trans-ancestry GRS.

It is essential that the human genetics research community takes advantage of the opportunities offered by the increasing availability of GWAS across ancestry groups and continues to bolster collections in underrepresented populations. In contrast to GWAS, multi-omics resources that are critical for the inference of effector genes and causal mechanisms through which complex trait association signals are mediated remain deficient for the very populations with the greatest burden of disease. Further methodological development is also critical to: (i) allow for increased levels of admixture within populations; (ii) enable fine-mapping of multiple causal variants at the same locus without the need for conditional analyses; and (iii) conduct trans-ancestry polygenic risk scores that take account of genome-wide SNVs because of different LD structure across diverse populations. Prioritising research in diverse populations to address these challenges will ultimately provide a more comprehensive and refined view of the genetic contribution to complex human traits, improving understanding of the molecular and biological processes underlying common diseases, and offering the most promising opportunities for clinical translation of GWAS findings to improve global public health. 
medRxiv preprint doi: https://doi.org/10.1101/2020.09.22.20198937; this version posted September $23,2020$. The copyright holder for this preprint (which was not certified by peer review) is the author/funder, who has granted medRxiv a license to display the preprint in perpetuity.

It is made available under a CC-BY 4.0 International license .

\section{REFERENCES}

1. B. F. Voight, L. J. Scott, V. Steinthorsdottir, A. P. Morris, C. Dina, R. P. Welch, E. Zeggini, C. Huth, Y. S. Aulchenko, G. Thorleifsson, L. J. McCulloch, T. Ferreira, H. Grallert, N. Amin, G. Wu, C. J. Willer, S. Raychaudhuri, S. A. McCarroll, C. Langenberg, O. M. Hofmann, J. Dupuis, L. Qi, A. V. Segrè, M. van Hoek, P. Navarro, K. Ardlie, B. Balkau, R. Benediktsson, A. J. Bennett, R. Blagieva, E. Boerwinkle, L. L. Bonnycastle, K. Bengtsson Boström, B. Bravenboer, S. Bumpstead, N. P. Burtt, G. Charpentier, P. S. Chines, M. Cornelis, D. J. Couper, G. Crawford, A. S. F. Doney, K. S. Elliott, A. L. Elliott, M. R. Erdos, C. S. Fox, C. S. Franklin, M. Ganser, C. Gieger, N. Grarup, T. Green, S. Griffin, C. J. Groves, C. Guiducci, S. Hadjadj, N. Hassanali, C. Herder, B. Isomaa, A. U. Jackson, P. R. V. Johnson, T. Jørgensen, W. H. L. Kao, N. Klopp, A. Kong, P. Kraft, J. Kuusisto, T. Lauritzen, M. Li, A. Lieverse, C. M. Lindgren, V. Lyssenko, M. Marre, T. Meitinger, K. Midthjell, M. A. Morken, N. Narisu, P. Nilsson, K. R. Owen, F. Payne, J. R. B. Perry, A.-K. Petersen, C. Platou, C. Proença, I. Prokopenko, W. Rathmann, N. W. Rayner, N. R. Robertson, G. Rocheleau, M. Roden, M. J. Sampson, R. Saxena, B. M. Shields, P. Shrader, G. Sigurdsson, T. Spars $\varnothing$, K. Strassburger, H. M. Stringham, Q. Sun, A. J. Swift, B. Thorand, J. Tichet, T. Tuomi, R. M. van Dam, T. W. van Haeften, T. van Herpt, J. V. van Vliet-Ostaptchouk, G. Bragi Walters, M. N. Weedon, C. Wijmenga, J. Witteman, The MAGIC investigators, The GIANT Consortium, R. N. Bergman, S. Cauchi, F. S. Collins, A. L. Gloyn, U. Gyllensten, T. Hansen, W. A. Hide, G. A. Hitman, A. Hofman, D. J. Hunter, K. Hveem, M. Laakso, K. L. Mohlke, A. D. Morris, C. N. A. Palmer, P. P. Pramstaller, I. Rudan, E. Sijbrands, L. D. Stein, J. Tuomilehto, A. Uitterlinden, M. Walker, N. J. Wareham, R. M. Watanabe, G. R. Abecasis, B. O. Boehm, H. Campbell, M. J. Daly, A. T. Hattersley, F. B. Hu, J. B. Meigs, J. S. Pankow, O. Pedersen, H.-E. Wichmann, I. Barroso, J. C. Florez, T. M. Frayling, L. Groop, R. Sladek, U. Thorsteinsdottir, J. F. Wilson, T. Illig, P. Froguel, C. M. van Duijn, K. Stefansson, D. Altshuler, M. Boehnke, M. I. McCarthy, Twelve type 2 diabetes susceptibility loci identified through large-scale association analysis. Nat. Genet. 42, 579-589 (2010).

2. A. P. Morris, B. F. Voight, T. M. Teslovich, T. Ferreira, A. V. Segrè, V. Steinthorsdottir, R. J. Strawbridge, H. Khan, H. Grallert, A. Mahajan, I. Prokopenko, H. M. Kang, C. Dina, T. Esko, R. M. Fraser, S. Kanoni, A. Kumar, V. Lagou, C. Langenberg, J. Luan, C. M. Lindgren, M. Müller-Nurasyid, S. Pechlivanis, N. W. Rayner, L. J. Scott, S. Wiltshire, L. Yengo, L. Kinnunen, E. J. Rossin, S. Raychaudhuri, A. D. Johnson, A. S. Dimas, R. J. Loos, S. Vedantam, H. Chen, J. C. Florez, C. Fox, C. T. Liu, D. Rybin, D. J. Couper, W. H. Kao, M. Li, M. C. Cornelis, P. Kraft, Q. Sun, R. M. van Dam, H. M. Stringham, P. S. Chines, K. Fischer, P. Fontanillas, O. L. Holmen, S. E. Hunt, A. U. Jackson, A. Kong, R. Lawrence, J. Meyer, J. R. Perry, C. G. Platou, S. Potter, E. Rehnberg, N. Robertson, S. Sivapalaratnam, A. Stančáková, K. Stirrups, G. Thorleifsson, E. Tikkanen, A. R. Wood, P. Almgren, M. Atalay, R. Benediktsson, L. L. Bonnycastle, N. Burtt, J. Carey, G. Charpentier, A. T. Crenshaw, A. S. Doney, M. Dorkhan, S. Edkins, V. Emilsson, E. Eury, T. Forsen, K. Gertow, B. Gigante, G. B. Grant, C. J. Groves, C. Guiducci, C. Herder, A. B. Hreidarsson, J. Hui, A. James, A. Jonsson, W. Rathmann, N. Klopp, J. Kravic, K. Krjutškov, C. Langford, K. Leander, E. Lindholm, S. Lobbens, S. Männistö, G. Mirza, T. W. Mühleisen, B. Musk, M. Parkin, L. Rallidis, J. Saramies, B. Sennblad, S. Shah, G. Sigurðsson, A. Silveira, G. Steinbach, B. Thorand, J. Trakalo, F. Veglia, R. Wennauer, W. Winckler, D. Zabaneh, H. Campbell, C. van Duijn, A. G. Uitterlinden, A. Hofman, E. 
medRxiv preprint doi: https://doi.org/10.1101/2020.09.22.20198937; this version posted September $23,2020$. The copyright holder for this preprint (which was not certified by peer review) is the author/funder, who has granted medRxiv a license to display the preprint in perpetuity.

It is made available under a CC-BY 4.0 International license .

Sijbrands, G. R. Abecasis, K. R. Owen, E. Zeggini, M. D. Trip, N. G. Forouhi, A. C. Syvänen, J. G. Eriksson, L. Peltonen, M. M. Nöthen, B. Balkau, C. N. Palmer, V. Lyssenko, T. Tuomi, B. Isomaa, D. J. Hunter, L. Qi, A. R. Shuldiner, M. Roden, I. Barroso, T. Wilsgaard, J. Beilby, K. Hovingh, J. F. Price, J. F. Wilson, R. Rauramaa, T. A. Lakka, L. Lind, G. Dedoussis, I. Njølstad, N. L. Pedersen, K. T. Khaw, N. J. Wareham, S. M. Keinanen-Kiukaanniemi, T. E. Saaristo, E. Korpi-Hyövälti, J. Saltevo, M. Laakso, J. Kuusisto, A. Metspalu, F. S. Collins, K. L. Mohlke, R. N. Bergman, J. Tuomilehto, B. O. Boehm, C. Gieger, K. Hveem, S. Cauchi, P. Froguel, D. Baldassarre, E. Tremoli, S. E. Humphries, D. Saleheen, J. Danesh, E. Ingelsson, S. Ripatti, V. Salomaa, R. Erbel, K. H. Jöckel, S. Moebus, A. Peters, T. Illig, U. de Faire, A. Hamsten, A. D. Morris, P. J.

Donnelly, T. M. Frayling, A. T. Hattersley, E. Boerwinkle, O. Melander, S. Kathiresan, P. M. Nilsson, P. Deloukas, U. Thorsteinsdottir, L. C. Groop, K. Stefansson, F. Hu, J. S. Pankow, J. Dupuis, J. B. Meigs, D. Altshuler, M. Boehnke, M. I. McCarthy, Large-scale association analysis provides insights into the genetic architecture and pathophysiology of type 2 diabetes. Nat. Genet. 44, 981-990 (2012).

3. R. A. Scott, L. J. Scott, R. Mägi, L. Marullo, K. J. Gaulton, M. Kaakinen, N. Pervjakova, T. H. Pers, A. D. Johnson, J. D. Eicher, A. U. Jackson, T. Ferreira, Y. Lee, C. Ma, V. Steinthorsdottir, G. Thorleifsson, L. Qi, N. R. Van Zuydam, A. Mahajan, H. Chen, P. Almgren, B. F. Voight, H. Grallert, M. Müller-Nurasyid, J. S. Ried, N. W. Rayner, N. Robertson, L. C. Karssen, E. M. van Leeuwen, S. M. Willems, C. Fuchsberger, P. Kwan, T. M. Teslovich, P. Chanda, M. Li, Y. Lu, C. Dina, D. Thuillier, L. Yengo, L. Jiang, T. Sparso, H. A. Kestler, H. Chheda, L. Eisele, S. Gustafsson, M. Frånberg, R. J. Strawbridge, R. Benediktsson, A. B. Hreidarsson, A. Kong, G. Sigurðsson, N. D. Kerrison, J. Luan, L. Liang, T. Meitinger, M. Roden, B. Thorand, T. Esko, E. Mihailov, C. Fox, C. T. Liu, D. Rybin, B. Isomaa, V. Lyssenko, T. Tuomi, D. J. Couper, J. S. Pankow, N. Grarup, C. T. Have, M. E. Jørgensen, T. Jørgensen, A. Linneberg, M. C. Cornelis, R. M. van Dam, D. J. Hunter, P. Kraft, Q. Sun, S. Edkins, K. R. Owen, J. R. B. Perry, A. R. Wood, E. Zeggini, J. Tajes-Fernandes, G. R. Abecasis, L. L. Bonnycastle, P. S. Chines, H. M. Stringham, H. A. Koistinen, L. Kinnunen, B. Sennblad, T. W. Mühleisen, M. M. Nöthen, S. Pechlivanis, D. Baldassarre, K. Gertow, S. E. Humphries, E. Tremoli, N. Klopp, J. Meyer, G. Steinbach, R. Wennauer, J. G. Eriksson, S. Männistö, L. Peltonen, E. Tikkanen, G. Charpentier, E. Eury, S. Lobbens, B. Gigante, K. Leander, O. McLeod, E. P. Bottinger, O. Gottesman, D. Ruderfer, M. Blüher, P. Kovacs, A. Tonjes, N. M. Maruthur, C. Scapoli, R. Erbel, K. H. Jöckel, S. Moebus, U. de Faire, A. Hamsten, M. Stumvoll, P. Deloukas, P. J. Donnelly, T. M. Frayling, A. T. Hattersley, S. Ripatti, V. Salomaa, N. L. Pedersen, B. O. Boehm, R. N. Bergman, F. S. Collins, K. L. Mohlke, J. Tuomilehto, T. Hansen, O. Pedersen, I. Barroso, L. Lannfelt, E. Ingelsson, L. Lind, C. M. Lindgren, S. Cauchi, P. Froguel, R. J. F. Loos, B. Balkau, H. Boeing, P. W. Franks, A. Barricarte Gurrea, D. Palli, Y. T. van der Schouw, D. Altshuler, L. C. Groop, C. Langenberg, N. J. Wareham, E. Sijbrands, C. M. van Duijn, J. C. Florez, J. B. Meigs, E. Boerwinkle, C. Gieger, K. Strauch, A. Metspalu, A. D. Morris, C. N. A. Palmer, F. B. Hu, U. Thorsteinsdottir, K. Stefansson, J. Dupuis, A. P. Morris, M. Boehnke, M. I. McCarthy, I. Prokopenko, An expanded genome-wide association study of type 2 diabetes in Europeans. Diabetes 66, 2888-2902 (2017).

4. A. Mahajan, D. Taliun, M. Thurner, N. R. Robertson, J. M. Torres, N. W. Rayner, A. J. Payne, V. Steinthorsdottir, R. A. Scott, N. Grarup, J. P. Cook, E. M. Schmidt, M. Wuttke, C. Sarnowski, R. Mägi, J. Nano, C. Gieger, S. Trompet, C. Lecoeur, M. H. 
medRxiv preprint doi: https://doi.org/10.1101/2020.09.22.20198937; this version posted September $23,2020$. The copyright holder for this preprint (which was not certified by peer review) is the author/funder, who has granted medRxiv a license to display the preprint in perpetuity.

It is made available under a CC-BY 4.0 International license .

Preuss, B. P. Prins, X. Guo, L. F. Bielak, J. E. Below, D. W. Bowden, J. C. Chambers, Y. J. Kim, M. C. Y. Ng, L. E. Petty, X. Sim, W. Zhang, A. J. Bennett, J. Bork-Jensen, C. M. Brummett, M. Canouil, K. U. Eckardt, K. Fischer, S. L. R. Kardia, F. Kronenberg, K. Läll, C. T. Liu, A. E. Locke, J. Luan, I. Ntalla, V. Nylander, S. Schönherr, C. Schurmann, L. Yengo, E. P. Bottinger, I. Brandslund, C. Christensen, G. Dedoussis, J. C. Florez, I. Ford, O. H. Franco, T. M. Frayling, V. Giedraitis, S. Hackinger, A. T. Hattersley, C. Herder, M. A. Ikram, M. Ingelsson, M. E. Jørgensen, T. Jørgensen, J. Kriebel, J. Kuusisto, S. Ligthart, C. M. Lindgren, A. Linneberg, V. Lyssenko, V. Mamakou, T. Meitinger, K. L. Mohlke, A. D. Morris, G. Nadkarni, J. S. Pankow, A. Peters, N. Sattar, A. Stančáková, K. Strauch, K. D. Taylor, B. Thorand, G. Thorleifsson, U.

Thorsteinsdottir, J. Tuomilehto, D. R. Witte, J. Dupuis, P. A. Peyser, E. Zeggini, R. J. F. Loos, P. Froguel, E. Ingelsson, L. Lind, L. Groop, M. Laakso, F. S. Collins, J. W. Jukema, C. N. A. Palmer, H. Grallert, A. Metspalu, A. Dehghan, A. Köttgen, G. R. Abecasis, J. B. Meigs, J. I. Rotter, J. Marchini, O. Pedersen, T. Hansen, C. Langenberg, N. J.

Wareham, K. Stefansson, A. L. Gloyn, A. P. Morris, M. Boehnke, M. I. McCarthy, Finemapping type 2 diabetes loci to single-variant resolution using high-density imputation and islet-specific epigenome maps. Nat. Genet. 50, 1505-1513 (2018).

5. K. Suzuki, M. Akiyama, K. Ishigaki, M. Kanai, J. Hosoe, N. Shojima, A. Hozawa, A. Kadota, K. Kuriki, M. Naito, K. Tanno, Y. Ishigaki, M. Hirata, K. Matsuda, N. Iwata, M. Ikeda, N. Sawada, T. Yamaji, M. Iwasaki, S. Ikegawa, S. Maeda, Y. Murakami, K. Wakai, S. Tsugane, M. Sasaki, M. Yamamoto, Y. Okada, M. Kubo, Y. Kamatani, M. Horikoshi, T. Yamauchi, T. Kadowaki, Identification of 28 new susceptibility loci for type 2 diabetes in the Japanese population. Nat. Genet. 51, 379-386 (2019).

6. C. N. Spracklen, M. Horikoshi, Y. J. Kim, K. Lin, F. Bragg, S. Moon, K. Suzuki, C. H. T. Tam, Y. Tabara, S. H. Kwak, F. Takeuchi, J. Long, V. J. Y. Lim, J. F. Chai, C. H. Chen, M. Nakatochi, J. Yao, H. S. Choi, A. K. Iyengar, H. J. Perrin, S. M. Brotman, M. van de Bunt, A. L. Gloyn, J. E. Below, M. Boehnke, D. W. Bowden, J. C. Chambers, A. Mahajan, M. I. McCarthy, M. C. Y. Ng, L. E. Petty, W. Zhang, A. P. Morris, L. S. Adair, M. Akiyama, Z. Bian, J. C. N. Chan, L. C. Chang, M. L. Chee, Y. I. Chen, Y. T. Chen, Z. Chen, L. M. Chuang, S. Du, P. Gordon-Larsen, M. Gross, X. Guo, Y. Guo, S. Han, A. G. Howard, W. Huang, Y. J. Hung, M. Y. Hwang, C. M. Hwu, S. Ichihara, M. Isono, H. M. Jang, G. Jiang, J. B. Jonas, Y. Kamatani, T. Katsuya, T. Kawaguchi, C. C. Khor, K. Kohara, M. S. Lee, N. R. Lee, L. Li, J. Liu, A. O. Luk, J. Lv, Y. Okada, M. A. Pereira, C. Sabanayagam, J. Shi, D. M. Shin, W. Y. So, A. Takahashi, B. Tomlinson, F. J. Tsai, R. M. van Dam, Y. B. Xiang, K. Yamamoto, T. Yamauchi, K. Yoon, C. Yu, J. M. Yuan, L. Zhang, W. Zheng, M. Igase, Y. S. Cho, J. I. Rotter, Y. X. Wang, W. H. H. Sheu, M. Yokota, J. Y. Wu, C. Y. Cheng, T. Y. Wong, X. O. Shu, N. Kato, K. S. Park, E. S. Tai, F. Matsuda, W. P. Koh, R. C. W. Ma, S. Maeda, I. Y. Millwood, J. Lee, T. Kadowaki, R. G. Walters, B. J. Kim, K. L. Mohlke, X. Sim, Identification of type 2 diabetes loci in 433,540 East Asian individuals. Nature 582, 240-245 (2020).

7. J. P. Cook, A. P. Morris, Multi-ethnic genome-wide association study identifies novel locus for type 2 diabetes susceptibility. Eur. J. Hum. Genet. 24, 1175-1180.

8. M. Vujkovic, J. M. Keaton, J. A. Lynch, D. R. Miller, J. Zhou, C. Tcheandjieu, J. E. Huffman, T. L. Assimes, K. Lorenz, X. Zhu, A. T. Hilliard, R. L. Judy, J. Huang, K. M. Lee, D. Klarin, S. Pyarajan, J. Danesh, O. Melander, A. Rasheed, N. H. Mallick, S. Hameed, I. H. Qureshi, M. N. Afzal, U. Malik, A. Jalal, S. Abbas, X. Sheng, L. Gao, K. H. Kaestner, K. Susztak, Y. V. Sun, S. L. DuVall, K. Cho, J. S. Lee, J. M. Gaziano, L. S. Phillips, J. B. 
Meigs, P. D. Reaven, P. W. Wilson, T. L. Edwards, D. J. Rader, S. M. Damrauer, C. J. O'Donnell, P. S. Tsao, K. M. Chang, B. F. Voight, D. Saleheen, M. A. Atkinson, A. C. Powers, A. Naji, K. H. Kaestner, G. R. Abecasis, A. Baras, M. N. Cantor, G. Coppola, A. N. Economides, L. A. Lotta, J. D. Overton, J. G. Reid, A. R. Shuldiner, C. Beechert, C. Forsythe, E. D. Fuller, Z. Gu, M. Lattari, A. E. Lopez, T. D. Schleicher, M. S. Padilla, K. Toledo, L. Widom, S. E. Wolf, M. Pradhan, K. Manoochehri, R. H. Ulloa, X. Bai, S. Balasubramanian, L. Barnard, A. L. Blumenfeld, G. Eom, L. Habegger, A. Hawes, S. Khalid, E. K. Maxwell, W. J. Salerno, J. C. Staples, A. Yadav, M. B. Jones, L. J. Mitnaul, S. M. Aguayo, S. K. Ahuja, Z. K. Ballas, S. Bhushan, E. J. Boyko, D. M. Cohen, J. Concato, J. I. Constans, L. J. Dellitalia, J. M. Fayad, R. S. Fernando, H. J. Florez, M. A. Gaddy, S. S. Gappy, G. Gibson, M. Godschalk, J. A. Greco, S. Gupta, S. Gutierrez, K. D. Hammer, M. B. Hamner, J. B. Harley, A. M. Hung, M. Huq, R. A. Hurley, P. R. Iruvanti, D. J. Ivins, F. J. Jacono, D. N. Jhala, L. S. Kaminsky, S. Kinlay, J. B. Klein, S. Liangpunsakul, J. H. Lichy, S. M. Mastorides, R. O. Mathew, K. M. Mattocks, R. McArdle, P. N. Meyer, L. J. Meyer, J. P. Moorman, T. R. Morgan, M. Murdoch, X. T. Nguyen, O. O. Okusaga, K. K. Oursler, N. R. Ratcliffe, M. I. Rauchman, R. B. Robey, G. W. Ross, R. J. Servatius, S. C. Sharma, S. E. Sherman, E. Sonel, P. Sriram, T. Stapley, R. T. Striker, N. Tandon, G. Villareal, A. S. Wallbom, J. M. Wells, J. C. Whittle, M. A. Whooley, J. Xu, S. S. Yeh, M. Aslan, J. V. Brewer, M. T. Brophy, T. Connor, D. P. Argyres, N. V. Do, E. R. Hauser, D. E. Humphries, L. E. Selva, S. Shayan, B. Stephens, S. B. Whitbourne, H. Zhao, J. Moser, J. C. Beckham, J. L. Breeling, J. P. C. Romero, G. D. Huang, R. B. Ramoni, S. Pyarajan, Y. V. Sun, K. Cho, P. W. Wilson, C. J. O'Donnell, P. S. Tsao, K. M. Chang, J. M. Gaziano, S. Muralidhar, Discovery of 318 new risk loci for type 2 diabetes and related vascular outcomes among 1.4 million participants in a multi-ancestry meta-analysis. Nat. Genet. 52, 680-691 (2020).

9. The 1000 Genomes Project Consortium, An integrated map of genetic variation from 1,092 human genomes. Nature 491, 56-65 (2012).

10. The 1000 Genomes Project Consortium, A global reference for human genetic variation. Nature 526, 68-74 (2015).

11. S. McCarthy, S. Das, W. Kretzschmar, O. Delaneau, A. R. Wood, A. Teumer, H. M. Kang, C. Fuchsberger, P. Danecek, K. Sharp, Y. Luo, C. Sidore, A. Kwong, N. Timpson, S. Koskinen, S. Vrieze, L. J. Scott, H. Zhang, A. Mahajan, J. Veldink, U. Peters, C. Pato, C. M. van Duijn, C. E. Gillies, I. Gandin, M. Mezzavilla, A. Gilly, M. Cocca, M. Traglia, A. Angius, J. C. Barrett, D. Boomsma, K. Branham, G. Breen, C. M. Brummett, F. Busonero, H. Campbell, A. Chan, S. Chen, E. Chew, F. S. Collins, L. J. Corbin, G. D. Smith, G. Dedoussis, M. Dorr, A. E. Farmaki, L. Ferrucci, L. Forer, R. M. Fraser, S. Gabriel, S. Levy, L. Groop, T. Harrison, A. Hattersley, O. L. Holmen, K. Hveem, M. Kretzler, J. C. Lee, M. McGue, T. Meitinger, D. Melzer, J. L. Min, K. L. Mohlke, J. B. Vincent, M. Nauck, D. Nickerson, A. Palotie, M. Pato, N. Pirastu, M. Mclnnis, J. B. Richards, C. Sala, V. Salomaa, D. Schlessinger, S. Schoenherr, P. E. Slagboom, K. Small, T. Spector, D. Stambolian, M. Tuke, J. Tuomilehto, L. H. Van den Berg, W. Van Rheenen, U. Volker, C. Wijmenga, D. Toniolo, E. Zeggini, P. Gasparini, M. G. Sampson, J. F. Wilson, T. Frayling, P. I. de Bakker, M. A. Swertz, S. McCarroll, C. Kooperberg, A. Dekker, D. Altshuler, C. Willer, W. Iacono, S. Ripatti, N. Soranzo, K. Walter, A. Swaroop, F. Cucca, C. A. Anderson, R. M. Myers, M. Boehnke, M. I. McCarthy, R. Durbin, G. Abecasis, J. Marchini, A reference panel of 64,976 haplotypes for genotype imputation. Nat. Genet. 48, 1279-1283 (2016). 
medRxiv preprint doi: https://doi.org/10.1101/2020.09.22.20198937; this version posted September $23,2020$. The copyright holder for this preprint (which was not certified by peer review) is the author/funder, who has granted medRxiv a license to display the preprint in perpetuity.

It is made available under a CC-BY 4.0 International license .

12. D. Gurdasani, I. Barroso, E. Zeggini, M. S. Sandhu, Genomics of disease risk in globally diverse populations. Nat. Rev. Genet. 20, 520-535 (2019).

13. R. Mägi, M. Horikoshi, T. Sofer, A. Mahajan, H. Kitajima, N. Franceschini, M. I. McCarthy, A. P. Morris, Trans-ethnic meta-regression of genome-wide association studies accounting for ancestry increases power for discovery and improves finemapping resolution. Hum. Mol. Genet. 26, 3639-3650 (2017).

14. H. Yaghootkar, L. A. Lotta, J. Tyrrell, R. A. Smit, S. E. Jones, L. Donnelly, R. Beaumont, A. Campbell, M. A. Tuke, C. Hayward, K. S. Ruth, S. Padmanabhan, J. W. Jukema, C. C. Palmer, A. Hattersley, R. M. Freathy, C. Langenberg, N. J. Wareham, A. R. Wood, A. Murray, M. N. Weedon, N. Sattar, E. Pearson, R. A. Scott, T. M. Frayling, Genetic evidence for a link between favorable adiposity and lower risk of type 2 diabetes, hypertension, and heart disease. Diabetes 65, 2448-2460 (2016).

15. M. Akiyama, Y. Okada, M. Kanai, A. Takahashi, Y. Momozawa, M. Ikeda, N. Iwata, S. Ikegawa, M. Hirata, K. Matsuda, M. Iwasaki, T. Yamaji, N. Sawada, T. Hachiya, K. Tanno, A. Shimizu, A. Hozawa, N. Minegishi, S. Tsugane, M. Yamamoto, M. Kubo, Y. Kamatani, Genome-wide association study identifies 112 new loci for body mass index in the Japanese population. Nat. Genet. 49, 1458-1467 (2017).

16. L. Yengo, J. Sidorenko, K. E. Kemper, Z. Zheng, A. R. Wood, M. N. Weedon, T. M. Frayling, J. Hirschhorn, J. Yang, P. M. Visscher, Meta-analysis of genome-wide association studies for height and body mass index in $\sim 700000$ individuals of European ancestry. Hum. Mol. Genet. 27, 3641-3649 (2018).

17. A. Mahajan, M. J. Go, W. Zhang, J. E. Below, K. J. Gaulton, T. Ferreira, M. Horikoshi, A. D. Johnson, M. C. Ng, I. Prokopenko, D. Saleheen, X. Wang, E. Zeggini, G. R. Abecasis, L. S. Adair, P. Almgren, M. Atalay, T. Aung, D. Baldassarre, B. Balkau, Y. Bao, A. H. Barnett, I. Barroso, A. Basit, L. F. Been, J. Beilby, G. I. Bell, R. Benediktsson, R. N. Bergman, B. O. Boehm, E. Boerwinkle, L. L. Bonnycastle, N. Burtt, Q. Cai, H. Campbell, J. Carey, S. Cauchi, M. Caulfield, J. C. Chan, L. C. Chang, T. J. Chang, Y. C. Chang, G. Charpentier, C. H. Chen, H. Chen, Y. T. Chen, K. S. Chia, M. Chidambaram, P. S. Chines, N. H. Cho, Y. M. Cho, L. M. Chuang, F. S. Collins, M. C. Cornelis, D. J. Couper, A. T. Crenshaw, R. M. van Dam, J. Danesh, D. Das, U. de Faire, G. Dedoussis, P. Deloukas, A. S. Dimas, C. Dina, A. S. Doney, P. J. Donnelly, M. Dorkhan, C. van Duijn, J. Dupuis, S. Edkins, P. Elliott, V. Emilsson, R. Erbel, J. G. Eriksson, J. Escobedo, T. Esko, E. Eury, J. C. Florez, P. Fontanillas, N. G. Forouhi, T. Forsen, C. Fox, R. M. Fraser, T. M. Frayling, P. Froguel, P. Frossard, Y. Gao, K. Gertow, C. Gieger, B. Gigante, H. Grallert, G. B. Grant, L. C. Grrop, C. J. Groves, E. Grundberg, C. Guiducci, A. Hamsten, B. G. Han, K. Hara, N. Hassanali, A. T. Hattersley, C. Hayward, A. K. Hedman, C. Herder, A. Hofman, O. L. Holmen, K. Hovingh, A. B. Hreidarsson, C. Hu, F. B. Hu, J. Hui, S. E. Humphries, S. E. Hunt, D. J. Hunter, K. Hveem, Z. I. Hydrie, H. Ikegami, T. Illig, E. Ingelsson, M. Islam, B. Isomaa, A. U. Jackson, T. Jafar, A. James, W. Jia, K. H. Jöckel, A. Jonsson, J. B. Jowett, T. Kadowaki, H. M. Kang, S. Kanoni, W. H. Kao, S. Kathiresan, N. Kato, P. Katulanda, K. M. Keinanen-Kiukaanniemi, A. M. Kelly, H. Khan, K. T. Khaw, C. C. Khor, H. L. Kim, S. Kim, Y. J. Kim, L. Kinnunen, N. Klopp, A. Kong, E. Korpi-Hyövälti, S. Kowlessur, P. Kraft, J. Kravic, M. M. Kristensen, S. Krithika, A. Kumar, J. Kumate, J. Kuusisto, S. H. Kwak, M. Laakso, V. Lagou, T. A. Lakka, C. Langenberg, C. Langford, R. Lawrence, K. Leander, J. M. Lee, N. R. Lee, M. Li, X. Li, Y. Li, J. Liang, S. Liju, W. Y. Lim, L. Lind, C. M. Lindgren, E. Lindholm, C. T. Liu, J. J. Liu, S. Lobbens, J. Long, R. J. Loos, W. Lu, J. Luan, V. Lyssenko, R. C. Ma, S. Maeda, R. Mägi, 
medRxiv preprint doi: https://doi.org/10.1101/2020.09.22.20198937; this version posted September $23,2020$. The copyright holder for this preprint (which was not certified by peer review) is the author/funder, who has granted medRxiv a license to display the preprint in perpetuity.

It is made available under a CC-BY 4.0 International license .

S. Männisto, D. R. Matthews, J. B. Meigs, O. Melander, A. Metspalu, J. Meyer, G. Mirza, E. Mihailov, S. Moebus, V. Mohan, K. L. Mohlke, A. D. Morris, T. W. Mühleisen, M. Müller-Nurasyid, B. Musk, J. Nakamura, E. Nakashima, P. Navarro, P. K. Ng, A. C. Nica, P. M. Nilsson, I. Njølstad, M. M. Nöthen, K. Ohnaka, T. H. Ong, K. R. Owen, C. N. Palmer, J. S. Pankow, K. S. Park, M. Parkin, S. Pechlivanis, N. L. Pedersen, L. Peltonen, J. R. Perry, A. Peters, J. M. Pinidiyapathirage, C. G. Platou, S. Potter, J. F. Price, L. Qi, V. Radha, L. Rallidis, A. Rasheed, W. Rathman, R. Rauramaa, S. Raychaudhuri, N. W. Rayner, S. D. Rees, E. Rehnberg, S. Ripatti, N. Robertson, M. Roden, E. J. Rossin, I. Rudan, D. Rybin, T. E. Saaristo, V. Salomaa, J. Saltevo, M. Samuel, D. K. Sanghera, J. Saramies, J. Scott, L. J. Scott, R. A. Scott, A. V. Segrè, J. Sehmi, B. Sennblad, N. Shah, S. Shah, A. S. Shera, X. O. Shu, A. R. Shuldiner, G. Sigurđsson, E. Sijbrands, A. Silveira, X. Sim, S. Sivapalaratnam, K. S. Small, W. Y. So, A. Stančáková, K. Stefansson, G. Steinbach, V. Steinthorsdottir, K. Stirrups, R. J. Strawbridge, H. M. Stringham, Q. Sun, C. Suo, A. C. Syvänen, R. Takayanagi, F. Takeuchi, W. T. Tay, T. M. Teslovich, B. Thorand, G. Thorleifsson, U. Thorsteinsdottir, E. Tikkanen, J. Trakalo, E. Tremoli, M. D. Trip, F. J. Tsai, T. Tuomi, J. Tuomilehto, A. G. Uitterlinden, A. Valladares-Salgado, S. Vedantam, F. Veglia, B. F. Voight, C. Wang, N. J. Wareham, R. Wennauer, A. R. Wickremasinghe, T. Wilsgaard, J. F. Wilson, S. Wiltshire, W. Winckler, T. Y. Wong, A. R. Wood, J. Y. Wu, Y. Wu, K. Yamamoto, T. Yamauchi, M. Yang, L. Yengo, M. Yokota, R. Young, D. Zabaneh, F. Zhang, R. Zhang, W. Zheng, P. Z. Zimmet, D. Altshuler, D. W. Bowden, Y. S. Cho, N. J. Cox, M. Cruz, C. L. Hanis, J. Kooner, J. Y. Lee, M. Seielstad, Y. Y. Teo, M. Boehnke, E. J. Parra, J. C. Chambers, E. S. Tai, M. I. McCarthy, A. P. Morris, Genome-wide trans-ancestry meta-analysis provides insight into the genetic architecture of type 2 diabetes susceptibility. Nat. Genet. 46, 234-244 (2014).

18. M. Horikoshi, L. Pasquali, S. Wiltshire, J. R. Huyghe, A. Mahajan, J. L. Asimit, T. Ferreira, A. E. Locke, N. R. Robertson, X. Wang, X. Sim, H. Fujita, K. Hara, R. Young, W. Zhang, S. Choi, H. Chen, I. Kaur, F. Takeuchi, P. Fontanillas, D. Thuillier, L. Yengo, J. E. Below, C. H. Tam, Y. Wu, G. Abecasis, D. Altshuler, G. I. Bell, J. Blangero, N. P. Burtt, R. Duggirala, J. C. Florez, C. L. Hanis, M. Seielstad, G. Atzmon, J. C. Chan, R. C. Ma, P. Froguel, J. G. Wilson, D. Bharadwaj, J. Dupuis, J. B. Meigs, Y. S. Cho, T. Park, J. S. Kooner, J. C. Chambers, D. Saleheen, T. Kadowaki, E. S. Tai, K. L. Mohlke, N. J. Cox, J. Ferrer, E. Zeggini, N. Kato, Y. Y. Teo, M. Boehnke, M. I. McCarthy, A. P. Morris, Transancestral fine-mapping of four type 2 diabetes susceptibility loci highlights potential causal regulatory mechanisms. Hum. Mol. Genet. 25, 2070-2081 (2016).

19. A. Mahajan, J. Wessel, S. M. Willems, W. Zhao, N. R. Robertson, A. Y. Chu, W. Gan, H. Kitajima, D. Taliun, N. W. Rayner, X. Guo, Y. Lu, M. Li, R. A. Jensen, Y. Hu, S. Huo, K. K. Lohman, W. Zhang, J. P. Cook, B. P. Prins, J. Flannick, N. Grarup, V. V. Trubetskoy, J. Kravic, Y. J. Kim, D. V. Rybin, H. Yaghootkar, M. Müller-Nurasyid, K. Meidtner, R. LiGao, T. V. Varga, J. Marten, J. Li, A. V. Smith, P. An, S. Ligthart, S. Gustafsson, G. Malerba, A. Demirkan, J. F. Tajes, V. Steinthorsdottir, M. Wuttke, C. Lecoeur, M. Preuss, L. F. Bielak, M. Graff, H. M. Highland, A. E. Justice, D. J. Liu, E. Marouli, G. M. Peloso, H. R. Warren, S. Afaq, S. Afzal, E. Ahlqvist, P. Almgren, N. Amin, L. B. Bang, A. G. Bertoni, C. Bombieri, J. Bork-Jensen, I. Brandslund, J. A. Brody, N. P. Burtt, M. Canouil, Y. I. Chen, Y. S. Cho, C. Christensen, S. V. Eastwood, K. U. Eckardt, K. Fischer, G. Gambaro, V. Giedraitis, M. L. Grove, H. G. de Haan, S. Hackinger, Y. Hai, S. Han, A. Tybjærg-Hansen, M. F. Hivert, B. Isomaa, S. Jäger, M. E. Jørgensen, T. Jørgensen, A. Käräjämäki, B. J. Kim, S. S. Kim, H. A. Koistinen, P. Kovacs, J. Kriebel, F. Kronenberg, K. 
medRxiv preprint doi: https://doi.org/10.1101/2020.09.22.20198937; this version posted September $23,2020$. The copyright holder for this preprint (which was not certified by peer review) is the author/funder, who has granted medRxiv a license to display the preprint in perpetuity.

It is made available under a CC-BY 4.0 International license .

Läll, L. A. Lange, J. J. Lee, B. Lehne, H. Li, K. H. Lin, A. Linneberg, C. T. Liu, J. Liu, M. Loh, R. Mägi, V. Mamakou, R. McKean-Cowdin, G. Nadkarni, M. Neville, S. F. Nielsen, I. Ntalla, P. A. Peyser, W. Rathmann, K. Rice, S. S. Rich, L. Rode, O. Rolandsson, S. Schönherr, E. Selvin, K. S. Small, A. Stančáková, P. Surendran, K. D. Taylor, T. M. Teslovich, B. Thorand, G. Thorleifsson, A. Tin, A. Tönjes, A. Varbo, D. R. Witte, A. R. Wood, P. Yajnik, J. Yao, L. Yengo, R. Young, P. Amouyel, H. Boeing, E. Boerwinkle, E. P. Bottinger, R. Chowdhury, F. S. Collins, G. Dedoussis, A. Dehghan, P. Deloukas, M. M. Ferrario, J. Ferrières, J. C. Florez, P. Frossard, V. Gudnason, T. B. Harris, S. R. Heckbert, J. M. M. Howson, M. Ingelsson, S. Kathiresan, F. Kee, J. Kuusisto, C. Langenberg, L. J. Launer, C. M. Lindgren, S. Männistö, T. Meitinger, O. Melander, K. L. Mohlke, M. Moitry, A. D. Morris, A. D. Murray, R. de Mutsert, M. Orho-Melander, K. R. Owen, M. Perola, A. Peters, M. A. Province, A. Rasheed, P. M. Ridker, F. Rivadineira, F. R. Rosendaal, A. H. Rosengren, V. Salomaa, W. H. Sheu, R. Sladek, B. H. Smith, K. Strauch, A. G. Uitterlinden, R. Varma, C. J. Willer, M. Blüher, A. S.

Butterworth, J. C. Chambers, D. I. Chasman, J. Danesh, C. van Duijn, J. Dupuis, O. H. Franco, P. W. Franks, P. Froguel, H. Grallert, L. Groop, B. G. Han, T. Hansen, A. T. Hattersley, C. Hayward, E. Ingelsson, S. L. R. Kardia, F. Karpe, J. S. Kooner, A. Köttgen, K. Kuulasmaa, M. Laakso, X. Lin, L. Lind, Y. Liu, R. J. F. Loos, J. Marchini, A. Metspalu, D. Mook-Kanamori, B. G. Nordestgaard, C. N. A. Palmer, J. S. Pankow, O. Pedersen, B. M. Psaty, R. Rauramaa, N. Sattar, M. B. Schulze, N. Soranzo, T. D. Spector, K. Stefansson, M. Stumvoll, U. Thorsteinsdottir, T. Tuomi, J. Tuomilehto, N. J. Wareham, J. G. Wilson, E. Zeggini, R. A. Scott, I. Barroso, T. M. Frayling, M. O. Goodarzi, J. B. Meigs, M. Boehnke, D. Saleheen, A. P. Morris, J. I. Rotter, M. I. McCarthy, Refining the accuracy of validated target identification through coding variant fine-mapping in type 2 diabetes. Nat. Genet. 50, 559-571 (2018).

20. A. Varshney, L. J. Scott, R. P. Welch, M. R. Erdos, P. S. Chines, N. Narisu, R. D. Albanus, P. Orchard, B. N. Wolford, R. Kursawe, S. Vadlamudi, M. E. Cannon, J. P. Didion, J. Hensley, A. Kirilusha, L. L. Bonnycastle, D. L. Taylor, R. Watanabe, K. L. Mohlke, M. Boehnke, F. S. Collins, S. C. Parker, M. L. Stitzel, B. B. Barnabas, G. G. Bouffard, S. Y. Brooks, H. Coleman, L. Dekhtyar, X. Guan, J. Han, S. L. Ho, R. Legaspi, Q. L. Maduro, C. A. Masiello, J. C. McDowell, C. Montemayor, J. C. Mullikin, M. Park, N. L. Riebow, J. Rosarda, K. Schandler, B. Schmidt, C. Sison, R. Smith, S. Stantripop, J. W. Thomas, P. J. Thomas, M. Vemulapalli, A. C. Young, Genetic regulatory signatures underlying islet gene expression and type 2 diabetes. Proc. Natl. Acad. Sci. U. S. A. 114, 2301-2306 (2017).

21. F. Zhao, F. Huang, M. Tang, X. Li, N. Zhang, A. Amfilochiadis, Y. Li, R. Hu, T. Jin, C. Peng, Q. Wang, Nodal induces apoptosis through activation of the ALK7 signaling pathway in pancreatic INS-1 $\beta$-cells. Am. J. Physiol. Endocrinol. Metab. 303, E132-43 (2012).

22. C. A. Emdin, A. V. Khera, K. Aragam, M. Haas, M. Chaffin, D. Klarin, P. Natarajan, A. Bick, S. M. Zekavat, A. Nomura, D. Ardissino, J. G. Wilson, H. Schunkert, R. McPherson, H. Watkins, R. Elosua, M. J. Bown, N. J. Samani, U. Baber, J. Erdmann, N. Gupta, J. Danesh, D. Saleheen, S. Gabriel, S. Kathiresan, DNA sequence variation in ACVR1C encoding the activin receptor-like kinase 7 influences body fat distribution and protects against type 2 diabetes. Diabetes 68, 226-234 (2019).

23. SIGMA Type 2 Diabetes Consortium, Sequence variants in SLC16A11 are a common risk factor for type 2 diabetes in Mexico. Nature 506, 97-101 (2014). 
24. V. Rusu, E. Hoch, J. M. Mercader, D. E. Tenen, M. Gymrek, C. R. Hartigan, M. DeRan, M. von Grotthuss, P. Fontanillas, A. Spooner, G. Guzman, A. A. Deik, K. A. Pierce, C. Dennis, C. B. Clish, S. A. Carr, B. K. Wagner, M. Schenone, M. C. Y. Ng, B. H. Chen, F. Centeno-Cruz, C. Zerrweck, L. Orozco, D. M. Altshuler, S. L. Schreiber, J. C. Florez, S. B. R. Jacobs, E. S. Lander, M. C. Y. Ng, D. Shriner, B. H. Chen, J. Li, W. M. Chen, X. Guo, J. Liu, S. J. Bielinski, L. R. Yanek, M. A. Nalls, M. E. Comeau, L. J. Rasmussen-Torvik, R. A. Jensen, D. S. Evans, Y. V. Sun, P. An, S. R. Patel, Y. Lu, J. Long, L. L. Armstrong, L. Wagenknecht, L. Yang, B. M. Snively, N. D. Palmer, P. Mudgal, C. D. Langefeld, K. L. Keene, B. I. Freedman, J. C. Mychaleckyj, U. Nayak, L. J. Raffel, M. O. Goodarzi, Y. I. Chen, H. A. Taylor, A. Correa, M. Sims, D. Couper, J. S. Pankow, E. Boerwinkle, A. Adeyemo, A. Doumatey, G. Chen, R. A. Mathias, D. Vaidya, A. B. Singleton, A. B. Zonderman, R. P. Igo, J. R. Sedor, E. K. Kabagambe, D. S. Siscovick, B. McKnight, K. Rice, Y. Liu, W. C. Hsueh, W. Zhao, L. F. Bielak, A. Kraja, M. A. Province, E. P. Bottinger, O. Gottesman, Q. Cai, W. Zheng, W. J. Blot, W. L. Lowe, J. A. Pacheco, D. C. Crawford, E. Grundberg, S. S. Rich, M. G. Hayes, X. O. Shu, R. J. F. Loos, I. B. Borecki, P. A. Peyser, S. R. Cummings, B. M. Psaty, M. Fornage, S. K. Iyengar, M. K. Evans, D. M. Becker, W. H. L. Kao, J. G. Wilson, J. I. Rotter, M. M. Sale, S. Liu, C. N. Rotimi, D. W. Bowden, J. M. Mercader, A. Huerta-Chagoya, H. García-Ortiz, H. Moreno-Macías, A. Manning, L. Caulkins, N. P. Burtt, J. Flannick, N. Patterson, C. A. Aguilar-Salinas, T. Tusié-Luna, D. Altshuler, J. C. Florez, A. Martínez-Hernández, F. Centeno-Cruz, F. M. Barajas-Olmos, C. Zerrweck, C. Contreras-Cubas, E. Mendoza-Caamal, C. RevillaMonsalve, S. Islas-Andrade, E. Córdova, X. Soberón, L. Orozco, C. GonzálezVillalpando, M. E. González-Villalpando, C. A. Haiman, L. Wilkens, L. Le Marchand, K. Monroe, L. Kolonel, O. Arellano-Campos, M. L. Ordóñez-Sánchez, M. RodríguezTorres, Y. Segura-Kato, R. Rodríguez-Guillén, I. Cruz-Bautista, L. L. Muñoz-Hernandez, T. Sáenz, D. Gómez, U. Alvirde, P. Almeda-Valdés, M. L. Cortes, Type 2 diabetes variants disrupt function of SLC16A11 through two distinct mechanisms. Cell 170, 199-212 (2017).

25. S. H. Kwak, J. Chae, S. Lee, S. Choi, B. K. Koo, J. W. Yoon, J. H. Park, B. Cho, M. K. Moon, S. Lim, Y. M. Cho, S. Moon, Y. J. Kim, S. Han, M. Y. Hwang, Y. S. Cho, M. S. Lee, H. C. Jang, H. M. Kang, T. Park, N. H. Cho, K. Kim, J. I. Kim, K. S. Park, Nonsynonymous variants in PAX4 and GLP1R are associated with type 2 diabetes in an East Asian population. Diabetes 67, 1892-1902 (2018).

26. B. B. Sun, J. C. Maranville, J. E. Peters, D. Stacey, J. R. Staley, J. Blackshaw, S. Burgess, T. Jiang, E. Paige, P. Surendran, C. Oliver-Williams, M. A. Kamat, B. P. Prins, S. K. Wilcox, E. S. Zimmerman, A. Chi, N. Bansal, S. L. Spain, A. M. Wood, N. W. Morrell, J. R. Bradley, N. Janjic, D. J. Roberts, W. H. Ouwehand, J. A. Todd, N. Soranzo, K. Suhre, D. S. Paul, C. S. Fox, R. M. Plenge, J. Danesh, H. Runz, A. S. Butterworth, Genomic atlas of the human plasma proteome. Nature 558, 73-79 (2018).

27. GTEx Consortium, Genetic effects on gene expression across human tissues. Nature 550, 204-213 (2017).

28. A. Vinuela et al. , https://www. biorxiv. org/content/10. 1101/655670v1 (2019).

29. C. Giambartolomei, D. Vukcevic, E. E. Schadt, L. Franke, A. D. Hingorani, C. Wallace, V. Plagnol, Bayesian test for colocalisation between pairs of genetic association studies using summary statistics. PLoS Genet. 10, e1004383 (2014).

30. M. van de Bunt, J. E. Manning Fox, X. Dai, A. Barrett, C. Grey, L. Li, A. J. Bennett, P. R. Johnson, R. V. Rajotte, K. J. Gaulton, E. T. Dermitzakis, P. E. MacDonald, M. I. 
medRxiv preprint doi: https://doi.org/10.1101/2020.09.22.20198937; this version posted September $23,2020$. The copyright holder for this preprint (which was not certified by peer review) is the author/funder, who has granted medRxiv a license to display the preprint in

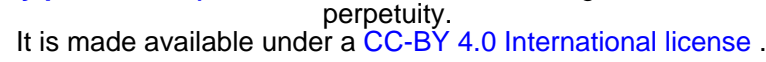

McCarthy, A. L. Gloyn, Transcript expression data from human islets links regulatory signals from genome-wide association studies for type 2 diabetes and glycemic traits to their downstream effectors. PLoS Genet. 11, e1005694 (2015).

31. T. S. Roman, M. E. Cannon, S. Vadlamudi, M. L. Buchkovich, B. N. Wolford, R. P. Welch, M. A. Morken, G. J. Kwon, A. Varshney, R. Kursawe, Y. Wu, A. U. Jackson, M. R. Erdos, J. Kuusisto, M. Laakso, L. J. Scott, M. Boehnke, F. S. Collins, S. C. J. Parker, M. L. Stitzel, K. L. Mohlke, A type 2 diabetes-associated functional regulatory variant in a pancreatic islet enhancer at the ADCY5 locus. Diabetes 66, 2521-2530 (2017).

32. G. R. Carrat, M. Hu, M. S. Nguyen-Tu, P. Chabosseau, K. J. Gaulton, M. van de Bunt, A. Siddiq, M. Falchi, M. Thurner, M. Canouil, F. Pattou, I. Leclerc, T. J. Pullen, M. C. Cane, P. Prabhala, W. Greenwald, A. Schulte, P. Marchetti, M. Ibberson, P. E. MacDonald, J. E. Manning Fox, A. L. Gloyn, P. Froguel, M. Solimena, M. I. McCarthy, G. A. Rutter, Decreased STARD10 expression is associated with defective insulin secretion in humans and mice. Am. J. Hum. Genet. 100, 238-256 (2017).

33. K. S. Small, M. Todorčević, M. Civelek, J. S. El-Sayed Moustafa, X. Wang, M. M. Simon, J. Fernandez-Tajes, A. Mahajan, M. Horikoshi, A. Hugill, C. A. Glastonbury, L. Quaye, M. J. Neville, S. Sethi, M. Yon, C. Pan, N. Che, A. Viñuela, P. C. Tsai, A. Nag, A. Buil, G. Thorleifsson, A. Raghavan, Q. Ding, A. P. Morris, J. T. Bell, U. Thorsteinsdottir, K. Stefansson, M. Laakso, I. Dahlman, P. Arner, A. L. Gloyn, K. Musunuru, A. J. Lusis, R. D. Cox, F. Karpe, M. I. McCarthy, Regulatory variants at KLF14 influence type 2 diabetes risk via a female-specific effect on adipocyte size and body composition. Nat. Genet. 50, 572-580 (2018).

34. M. Thurner, M. van de Bunt, J. M. Torres, A. Mahajan, V. Nylander, A. J. Bennett, K. J. Gaulton, A. Barrett, C. Burrows, C. G. Bell, R. Lowe, S. Beck, V. K. Rakyan, A. L. Gloyn, M. I. McCarthy, Integration of human pancreatic islet genomic data refines regulatory mechanisms at type 2 diabetes susceptibility loci. Elife 7, e31977 (2018).

35. D. Z. Pan, K. M. Garske, M. Alvarez, Y. V. Bhagat, J. Boocock, E. Nikkola, Z. Miao, C. K. Raulerson, R. M. Cantor, M. Civelek, C. A. Glastonbury, K. S. Small, M. Boehnke, A. J. Lusis, J. S. Sinsheimer, K. L. Mohlke, M. Laakso, P. Pajukanta, A. Ko, Integration of human adipocyte chromosomal interactions with adipose gene expression prioritizes obesity-related genes from GWAS. Nat. Commun. 9, 1512 (2018).

36. I. Miguel-Escalada, S. Bonàs-Guarch, I. Cebola, J. Ponsa-Cobas, J. Mendieta-Esteban, G. Atla, B. M. Javierre, D. M. Y. Rolando, I. Farabella, C. C. Morgan, J. García-Hurtado, A. Beucher, I. Morán, L. Pasquali, M. Ramos-Rodríguez, E. V. R. Appel, A. Linneberg, A. P. Gjesing, D. R. Witte, O. Pedersen, N. Grarup, P. Ravassard, D. Torrents, J. M. Mercader, L. Piemonti, T. Berney, E. J. P. de Koning, J. Kerr-Conte, F. Pattou, I. O. Fedko, L. Groop, I. Prokopenko, T. Hansen, M. A. Marti-Renom, P. Fraser, J. Ferrer, Human pancreatic islet three-dimensional chromatin architecture provides insights into the genetics of type 2 diabetes. Nat. Genet. 51, 1137-1148 (2019).

37. A. Chesi, Y. Wagley, M. E. Johnson, E. Manduchi, C. Su, S. Lu, M. E. Leonard, K. M. Hodge, J. A. Pippin, K. D. Hankenson, A. D. Wells, S. F. A. Grant, Genome-scale Capture C promoter interactions implicate effector genes at GWAS loci for bone mineral density. Nat. Commun. 10, 1260 (2019).

38. J. Chiou et al. , https://www. biorxiv. org/content/10. 1101/693671v1 (2019).

39. F. Esteghamat, J. S. Broughton, E. Smith, R. Cardone, T. Tyagi, M. Guerra, A. Szabó, N. Ugwu, M. V. Mani, B. Azari, G. Kayingo, S. Chung, M. Fathzadeh, E. Weiss, J. Bender, S. Mane, R. P. Lifton, A. Adeniran, M. H. Nathanson, F. S. Gorelick, J. Hwa, M. Sahin- 
medRxiv preprint doi: https://doi.org/10.1101/2020.09.22.20198937; this version posted September $23,2020$. The copyright holder for this preprint (which was not certified by peer review) is the author/funder, who has granted medRxiv a license to display the preprint in perpetuity.

It is made available under a CC-BY 4.0 International license .

Tóth, R. Belfort-DeAguiar, R. G. Kibbey, A. Mani, CELA2A mutations predispose to early-onset atherosclerosis and metabolic syndrome and affect plasma insulin and platelet activation. Nat. Genet. 51, 1233-1243 (2019).

40. N. H. J. Ng et al. , https://www. biorxiv. org/content/10. 1101/790618v1 (2019).

41. A. L. Gloyn, Exocrine or endocrine? A circulating pancreatic elastase that regulates glucose homeostasis. Nat. Metab. 1, 853-855 (2019).

42. A. Wesolowska-Andersen, G. Zhuo Yu, V. Nylander, F. Abaitua, M. Thurner, J. M. Torres, A. Mahajan, A. L. Gloyn, M. I. McCarthy, Deep learning models predict regulatory variants in pancreatic islets and refine type 2 diabetes association signals. Elife 9, e51503 (2020).

43. A. R. Martin, M. Kanai, Y. Kamatani, Y. Okada, B. M. Neale, M. J. Daly, Clinical use of current polygenic risk scores may exacerbate health disparities. Nat. Genet. 51, 584591 (2019).

44. Q. Ayub, L. Moutsianas, Y. Chen, K. Panoutsopoulou, V. Colonna, L. Pagani, I. Prokopenko, G. R. Ritchie, C. Tyler-Smith, M. I. McCarthy, E. Zeggini, Y. Xue, Revisiting the thrifty gene hypothesis via 65 loci associated with susceptibility to type 2 diabetes. Am. J. Hum. Genet. 94, 176-185 (2014).

45. J. V. Neel, Diabetes mellitus: a "thrifty" genotype rendered detrimental by "progress"? Am. J. Hum. Genet. 14, 353-362 (1962).

46. L. Speidel, M. Forest, S. Shi, S. R. Myers, A method for genome-wide genealogy estimation for thousands of samples. Nat. Genet. 51, 1321-1329 (2019).

47. C. Bycroft, C. Freeman, D. Petkova, G. Band, L. T. Elliott, K. Sharp, A. Motyer, D. Vukcevic, O. Delaneau, J. O'Connell, A. Cortes, S. Welsh, A. Young, M. Effingham, G. McVean, S. Leslie, N. Allen, P. Donnelly, J. Marchini, The UK Biobank resource with deep phenotyping and genomic data. Nature 562, 203-209 (2018).

48. R. Chen, E. Corona, M. Sikora, J. T. Dudley, A. A. Morgan, A. Moreno-Estrada, G. B. Nilsen, D. Ruau, S. E. Lincoln, C. D. Bustamante, A. J. Butte, Type 2 diabetes risk alleles demonstrate extreme directional differentiation among human populations, compared to other diseases. PLoS Genet. 8, e1002621 (2012).

49. NCD Risk Factor Collaboration, Worldwide trends in diabetes since 1980: a pooled analysis of 751 population-based studies with 4.4 million participants. Lancet 387, 1513-1530 (2016).

50. Y. Zheng, S. H. Ley, F. B. Hu, Global aetiology and epidemiology of type 2 diabetes mellitus and its complications. Nat. Rev. Endocrinol. 14, 88-98 (2018).

51. K. J. Nadeau, B. J. Anderson, E. G. Berg, J. L. Chiang, H. Chou, K. C. Copeland, T. S. Hannon, T. T. Huang, J. L. Lynch, J. Powell, E. Sellers, W. V. Tamborlane, P. Zeitler, Youth-onset type 2 diabetes consensus report: current status, challenges, and priorities. Diabetes Care 39, 1635-1642 (2016).

52. C. Y. Osborn, M. de Groot, J. A. Wagner, Racial and ethnic disparities in diabetes complications in the northeastern United States: the role of socioeconomic status. J. Natl. Med. Assoc. 105, 51-58 (2013).

53. H. Jónsson, P. Sulem, B. Kehr, S. Kristmundsdottir, F. Zink, E. Hjartarson, M. T. Hardarson, K. E. Hjorleifsson, H. P. Eggertsson, S. A. Gudjonsson, L. D. Ward, G. A. Arnadottir, E. A. Helgason, H. Helgason, A. Gylfason, A. Jonasdottir, A. Jonasdottir, T. Rafnar, S. Besenbacher, M. L. Frigge, S. N. Stacey, O. T. Magnusson, U. Thorsteinsdottir, G. Masson, A. Kong, B. V. Halldorsson, A. Helgason, D. F. 
medRxiv preprint doi: https://doi.org/10.1101/2020.09.22.20198937; this version posted September $23,2020$. The copyright holder for this preprint (which was not certified by peer review) is the author/funder, who has granted medRxiv a license to display the preprint in

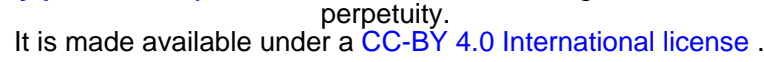

Gudbjartsson, K. Stefansson, Whole genome characterization of sequence diversity of 15,220 Icelanders. Sci. Data 4, 170115 (2017).

54. M. Mitt, M. Kals, K. Pärn, S. B. Gabriel, E. S. Lander, A. Palotie, S. Ripatti, A. P. Morris, A. Metspalu, T. Esko, R. Mägi, P. Palta, Improved imputation accuracy of rare and low-frequency variants using population-specific high-coverage WGS-based imputation reference panel. Eur. J. Hum. Genet. 25, 869-876 (2017).

55. S. Moon, Y. J. Kim, S. Han, M. Y. Hwang, D. M. Shin, M. Y. Park, Y. Lu, K. Yoon, H. M. Jang, Y. K. Kim, T. J. Park, D. S. Song, J. K. Park, J. E. Lee, B. J. Kim, The Korea Biobank Array: design and identification of coding variants associated with blood biochemical traits. Sci. Rep. 9, 1382 (2019).

56. J. P. Cook, A. Mahajan, A. P. Morris, Guidance for the utility of linear models in metaanalysis of genetic association studies of binary phenotypes. Eur. J. Hum. Genet. 25, 240-245 (2016).

57. B. Devlin, K. Roeder, Genomic control for association studies. Biometrics 55, $997-$ 1004 (1999).

58. C. J. Willer, Y. Li, G. R. Abecasis, METAL: fast and efficient meta-analysis of genomewide association scans. Bioinformatics 26, 2190-2191 (2010).

59. B. Han, E. Eskin, Random-effects model aimed at discovering associations in metaanalysis of genome-wide association studies. Am. J. Hum. Genet. 88, 586-598 (2011).

60. S. Purcell, B. Neale, K. Todd-Brown, L. Thomas, M. A. Ferreira, D. Bender, J. Maller, P. Sklar, P. I. de Bakker, M. J. Daly, P. C. Sham, PLINK: a tool set for whole-genome association and population-based linkage analyses. Am. J. Hum. Genet. 81, 559-575 (2007).

61. R. S. Sobota, D. Shriner, N. Kodaman, R. Goodloe, W. Zheng, Y. T. Gao, T. L. Edwards, C. I. Amos, S. M. Williams, Addressing population-specific multiple testing burdens in genetic association studies. Ann. Hum. Genet. 79, 136-147 (2015).

62. C. C. Spencer, Z. Su, P. Donnelly, J. Marchini, Designing genome-wide association studies: sample size, power, imputation, and the choice of genotyping chip. PLoS Genet. 5, e1000477 (2009).

63. J. Yang, T. Ferreira, A. P. Morris, S. E. Medland, P. A. Madden, A. C. Heath, N. G. Martin, G. W. Montgomery, M. N. Weedon, R. J. Loos, T. M. Frayling, M. I. McCarthy, J. N. Hirschhorn, M. E. Goddard, P. M. Visscher, Conditional and joint multiple-SNP analysis of GWAS summary statistics identifies additional variants influencing complex traits. Nat. Genet. 44, 369-375 (2012).

64. G. Schwarz, Estimating the dimension of a model. Ann. Statist. 6, 461-464 (1978).

65. J. B. Maller, G. McVean, J. Byrnes, D. Vukcevic, K. Palin, Z. Su, J. M. Howson, A. Auton, S. Myers, A. Morris, M. Pirinen, M. A. Brown, P. R. Burton, M. J. Caulfield, A. Compston, M. Farrall, A. S. Hall, A. T. Hattersley, A. V. Hill, C. G. Mathew, M. Pembrey, J. Satsangi, M. R. Stratton, J. Worthington, N. Craddock, M. Hurles, W. Ouwehand, M. Parkes, N. Rahman, A. Duncanson, J. A. Todd, D. P. Kwiatkowski, N. J. Samani, S. C. Gough, M. I. McCarthy, P. Deloukas, P. Donnelly, Bayesian refinement of association signals for 14 loci in 3 common diseases. Nat. Genet. 44, 1294-1301 (2012).

66. M. L. Freedman, D. Reich, K. L. Penney, G. J. McDonald, A. A. Mignault, N. Patterson, S. B. Gabriel, E. J. Topol, J. W. Smoller, C. N. Pato, M. T. Pato, T. L. Petryshen, L. N. Kolonel, E. S. Lander, P. Sklar, B. Henderson, J. N. Hirschhorn, D. Altshuler, Assessing 
medRxiv preprint doi: https://doi.org/10.1101/2020.09.22.20198937; this version posted September $23,2020$. The copyright holder for this preprint (which was not certified by peer review) is the author/funder, who has granted medRxiv a license to display the preprint in perpetuity.

It is made available under a CC-BY 4.0 International license .

the impact of population stratification on genetic association studies. Nat. Genet. 36, 388-393 (2004).

67. J. Harrow, A. Frankish, J. M. Gonzalez, E. Tapanari, M. Diekhans, F. Kokocinski, B. L. Aken, D. Barrell, A. Zadissa, S. Searle, I. Barnes, A. Bignell, V. Boychenko, T. Hunt, M. Kay, G. Mukherjee, J. Rajan, G. Despacio-Reyes, G. Saunders, C. Steward, R. Harte, M. Lin, C. Howald, A. Tanzer, T. Derrien, J. Chrast, N. Walters, S. Balasubramanian, B. Pei, M. Tress, J. M. Rodriguez, I. Ezkurdia, J. van Baren, M. Brent, D. Haussler, M. Kellis, A. Valencia, A. Reymond, M. Gerstein, R. Guigó, T. J. Hubbard, GENCODE: the reference human genome annotation for The ENCODE Project. Genome Res. 22, 1760-1774 (2012).

68. ENCODE Project Consortium, An integrated encyclopedia of DNA elements in the human genome. Nature 489, 57-74 (2012).

69. L. Pasquali, K. J. Gaulton, S. A. Rodríguez-Seguí, L. Mularoni, I. Miguel-Escalada, i. Akerman, J. J. Tena, I. Morán, C. Gómez-Marín, M. van de Bunt, J. Ponsa-Cobas, N. Castro, T. Nammo, I. Cebola, J. García-Hurtado, M. A. Maestro, F. Pattou, L. Piemonti, T. Berney, A. L. Gloyn, P. Ravassard, J. L. G. Skarmeta, F. Müller, M. I. McCarthy, J. Ferrer, Pancreatic islet enhancer clusters enriched in type 2 diabetes risk-associated variants. Nat. Genet. 46, 136-143 (2014).

70. J. Pickrell, Joint analysis of functional genomic data and genome-wide association studies of 18 human traits. Am. J. Hum. Genet. 94, 559-573 (2014).

71. J. A. Wakefield, Bayesian measure of the probability of false discovery in genetic epidemiology studies. Am. J. Hum. Genet. 81, 208-227 (2007).

72. P. Ravassard, Y. Hazhouz, S. Pechberty, E. Bricout-Neveu, M. Armanet, P. Czernichow, R. Scharfmann, A genetically engineered human pancreatic $\beta$ cell line exhibiting glucose-inducible insulin secretion. J. Clin. Invest. 121, 3589-3597 (2011).

73. Z. Dastani, M. F. Hivert, N. Timpson, J. R. Perry, X. Yuan, R. A. Scott, P. Henneman, I. M. Heid, J. R. Kizer, L. P. Lyytikäinen, C. Fuchsberger, T. Tanaka, A. P. Morris, K. Small, A. Isaacs, M. Beekman, S. Coassin, K. Lohman, L. Qi, S. Kanoni, J. S. Pankow, H. W. Uh, Y. Wu, A. Bidulescu, L. J. Rasmussen-Torvik, C. M. Greenwood, M. Ladouceur, J. Grimsby, A. K. Manning, C. T. Liu, J. Kooner, V. E. Mooser, P. Vollenweider, K. A. Kapur, J. Chambers, N. J. Wareham, C. Langenberg, R. Frants, K. Willems-Vandijk, B. A. Oostra, S. M. Willems, C. Lamina, T. W. Winkler, B. M. Psaty, R. P. Tracy, J. Brody, I. Chen, J. Viikari, M. Kähönen, P. P. Pramstaller, D. M. Evans, B. St Pourcain, N. Sattar, A. R. Wood, S. Bandinelli, O. D. Carlson, J. M. Egan, S. Böhringer, D. van Heemst, L. Kedenko, K. Kristiansson, M. L. Nuotio, B. M. Loo, T. Harris, M. Garcia, A. Kanaya, M. Haun, N. Klopp, H. E. Wichmann, P. Deloukas, E. Katsareli, D. J. Couper, B. B. Duncan, M. Kloppenburg, L. S. Adair, J. B. Borja, J. G. Wilson, S. Musani, X. Guo, T. Johnson, R. Semple, T. M. Teslovich, M. A. Allison, S. Redline, S. G. Buxbaum, K. L. Mohlke, I. Meulenbelt, C. M. Ballantyne, G. V. Dedoussis, F. B. Hu, Y. Liu, B. Paulweber, T. D. Spector, P. E. Slagboom, L. Ferrucci, A. Jula, M. Perola, O. Raitakari, J. C. Florez, V. Salomaa, J. G. Eriksson, T. M. Frayling, A. A. Hicks, T. Lehtimäki, G. D. Smith, D. S. Siscovick, F. Kronenberg, C. van Duijn, R. J. Loos, D. M. Waterworth, J. B. Meigs, J. Dupuis, J. B. Richards, Novel loci for adiponectin levels and their influence on type 2 diabetes and metabolic traits: a multi-ethnic meta-analysis of 45,891 individuals. PLoS Genet. 8, e1002607 (2012). 
medRxiv preprint doi: https://doi.org/10.1101/2020.09.22.20198937; this version posted September 23, 2020. The copyright holder for this preprint (which was not certified by peer review) is the author/funder, who has granted medRxiv a license to display the preprint in

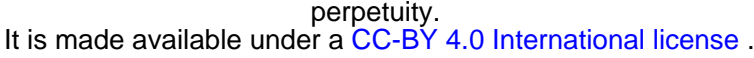

74. S. R. Browning, B. L. Browning, Rapid and accurate haplotype phasing and missing data inference for whole genome association studies by use of localized haplotype clustering. Am. J. Hum. Genet. 81, 1084-1097 (2007).

75. L. A. C. Millard, N. M. Davies, T. R. Gaunt, G. Davey Smith, K. Tilling, PHESANT: a tool for performing automated phenome scans in UK Biobank. Int. J. Epidemiol. 47, 29-35 (2018). 
medRxiv preprint doi: https://doi.org/10.1101/2020.09.22.20198937; this version posted September $23,2020$. The copyright holder for this preprint (which was not certified by peer review) is the author/funder, who has granted medRxiv a license to display the preprint in

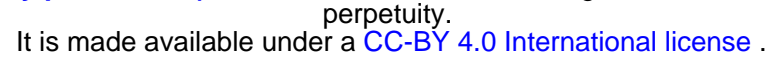

\section{ACKNOWLEDGEMENTS}

A full list of acknowledgments and funding appears in Supplementary Note 2.

Author contributions. DIAMANTE Consortium co-ordination: A.Mahajan, M.I.M., A.P.M. Manuscript preparation: A.Mahajan, C.N.S., W.Zhang, M.C.Y.N., L.E.P., H.K., G.Z.Y., S.Rüeger, L.S., A.L.G., M.B., J.I.R., M.I.M., A.P.M. Co-ordination of ancestry-specific GWAS collections: A.Mahajan, C.N.S., W.Zhang, M.C.Y.N., L.E.P., D.W.B., J.E.B., J.C.C., X.S., M.B. Central analysis group: A.Mahajan, C.N.S., W.Zhang, M.C.Y.N., L.E.P., H.K., Y.J.K., M.Horikoshi, J.M.M., D.T., S.Moon, S.-H.K., N.R.R., N.W.R., M.Loh, B.-J.K., J.B.M., K.L.M., J.E.B., J.C.C., X.S., M.B., J.I.R., M.I.M., A.P.M. PROX1 functional analyses: G.Z.Y., F.A., J.M.T., A.L.G. GRS analyses in FinnGen: S.Rüeger, P.d.B.P. Selection analyses: L.S., S.R.M. Single cell chromatin accessibility data: J.Chiou, D.G., S.P., M.Sander, K.J.G. Islet promoter HiC data generation: I.M.-E., J.F. Study-level primary analyses: A.Mahajan, C.N.S., W.Zhang, M.C.Y.N., L.E.P., Y.J.K., M.Horikoshi, J.M.M., D.T., S.Moon, S.-H.K., K.Lin, F.B., M.H.P., F.T., J.N., X.G., A.Lamri, M.N., R.A.S., J.-J.L., A.H.-G., M.Graff, J.-F.C., E.J.P., J.Y., L.F.B., Y.T., Y.H., V.S., J.P.C., M.K., N.G., E.M.S., I.P., T.S., M.W., C.Sarnowski, C.G., D.N., S.Trompet, J.Long, M.Sun, L.T., W.-M.C., M.Ahmad, R.N., V.J.Y.L., C.H.T.T., Y.Y.J., C.-H.C., L.M.R., C.Lecoeur, N.M.M., B.P.P., A.N., L.R.Y., G.C., R.A.J., S.Tajuddin, E.K., P.A., A.H.X., H.S.C., B.E.C., J.Tan, X.S., A.P.M. $\underline{\text { Study-level }}$ phenotyping, genotyping and additional analyses: Y.Y.J., L.S.A., A.A., C.A.A.-S., M.Akiyama, S.S.A., A.B., Z.B., J.B.-J., I.B., J.A.B., C.M.B., T.B., M.Canouil, J.C.N.C, L.-C.C., M.L.C., J.Chen, S.H.C., Y.-T.C., Z.C., C.C., L.-M.C., M.Cushman, S.K.D., H.J.d.S., G.D., L.D., A.P.D., S.D., Q.D., K.U.E., L.S.E., D.S.E., M.K.E., K.F., J.S.F., I.F., M.F., O.H.F., T.M.F., B.I.F., C.F., P.G., H.C.G., V.G., C.G.-V., M.E.G.-V., M.O.G., P.G.-L., M.Gross, Y.G., S.Hackinger, S.Han, A.T.H., C.H., A.-G.H., W.Hsueh, M.Huang, W.Huang, Y.-J.H., M.Y.H., C.-M.H., S.I., M.A.I., M.Ingelsson, M.T.I., M.Isono, H.-M.J., F.J., G.J., J.B.J., M.E.J., T.J., Y.K., F.R.K., A.Kasturiratne, T.Katsuya, V.K., T.Kawaguchi, J.M.K., A.N.K., C.-C.K., M.G.K., K.K., J.Kriebel, F.K., J.Kuusisto, K.Läll, L.A.L., M.S.L., N.R.L., A.Leong, L.Li, Y.Li, R.L.-G., S.Ligthart, C.M.L., A.Linneberg, C.-T.L., J.Liu, A.E.L., T.L., J.Luan, A.O.L., X.L., J.Lv, V.L., V.M., K.R.M., T.M., A.Metspalu, A.D.M., G.N.N., J.L.N., M.A.N., U.N., I.N., Y.O., L.O., S.R.P., M.A.Pereira, A.P., F.J.P., B.P., G.Prasad, L.J.R.-T., A.P.R, M.R., R.R., K.R., C.Sabanayagam, K.Sandow, N.S., S.S., C.Schurmann, M.Shahriar, J.S., D.M.S., D.Shriner, J.A.S., W.Y.S., A.S., A.M.S., K.Strauch, K.Suzuki, A.T., K.D.T., B.Thorand, G.T., U.T., B.Tomlinson, F.-J.T., J.Tuomilehto, T.T.-L., M.S.U., A.V.-S., R.M.v.D., J.B.v.K., R.V., M.V., N.W.R., E.W., E.A.W., A.R.W., K.W.v.D., D.R.W., Y.-B.X., C.S.Y., K.Yamamoto, T.Y., L.Y., K.Yoon, C.Y., J.-M.Y., S.Y., L.Z., W.Zheng. Study-level principal investigator: L.J.R., M.Igase, E.Ipp, S.Redline, Y.S.C., L.Lind, M.A.Province, C.L.H., P.A.P., E.Ingelsson, A.B.Z., B.M.P., Y.-X.W., C.N.R., D.M.B., F.M., Y.Liu, E.Z., M.Y., S.S.R., C.K., J.S.P., J.C.E., Y.-D.I.C., P.F., J.G.W., W.H.H.S., S.L.R.K., J.-Y.W., M.G.H., R.C.W.M., T.-Y.W., L.G., D.O.M.-K., G.R.C., F.S.C., D.B., G.Pare, M.M.S., H.A., A.A.M., X.-O.S., K.-S.P., J.W.J., M.Cruz, R.M.-C., H.G., C.-Y.C., E.P.B., A.D., E.S.T., J.D., N.K., M.Laakso, A.Köttgen, W.-P.K., C.N.A.P., S.Liu, G.A., J.S.K., R.J.F.L., K.E.N., C.A.H., J.C.F., D.Saleheen, T.H., O.P., R.M., C.Langenberg, N.J.W., S.Maeda, T.Kadowaki, J.Lee, I.Y.M., R.G.W., K.Stefansson, J.B.M., K.L.M., D.W.B., J.C.C., M.B., J.I.R., M.I.M., A.P.M.

Competing interests. A.Mahajan is now an employee of Genentech and a holder of Roche stock. V.S., G.T., U.T. and K.Stefansson are employees of deCODE genetics/Amgen Inc. J.S.F. has consulted for Shionogi Inc. H.C.G. holds the McMaster-Sanofi Population Health Institute Chair in Diabetes Research and Care; reports research grants from Eli Lilly, 
medRxiv preprint doi: https://doi.org/10.1101/2020.09.22.20198937; this version posted September 23, 2020. The copyright holder for this preprint (which was not certified by peer review) is the author/funder, who has granted medRxiv a license to display the preprint in It is made available under a CC-BY 4.0 International license .

AstraZeneca, Merck, Novo Nordisk and Sanofi; honoraria for speaking from AstraZeneca, Boehringer Ingelheim, Eli Lilly, Novo Nordisk, and Sanofi; and consulting fees from Abbott, AstraZeneca, Boehringer Ingelheim, Eli Lilly, Merck, Novo Nordisk, Janssen, Sanofi, and Kowa. S.R.P. has received grant funding from Bayer Pharmaceuticals, Philips Respironics and Respicardia. E.Ingelsson is now an employee of GlaxoSmithKline. B.M.P serves on the DSMB of a clinical trial funded by the manufacturer (Zoll LifeCor) and on the Steering Committee of the Yale Open Data Access Project funded by Johnson \& Johnson. D.O.M.-K. is a part-time clinical research consultant for Metabolon Inc. S.Liu reports consulting payments and honoraria or promises of the same for scientific presentations or reviews at numerous venues, including but not limited to Barilla, by-Health Inc, Ausa Pharmed Co.LTD, Fred Hutchinson Cancer Center, Harvard University, University of Buffalo, Guangdong General Hospital and Academy of Medical Sciences, Consulting member for Novo Nordisk, Inc; member of the Data Safety and Monitoring Board for a trial of pulmonary hypertension in diabetes patients at Massachusetts General Hospital; receives royalties from UpToDate; receives an honorarium from the American Society for Nutrition for his duties as Associate Editor. M.I.M. has served on advisory panels for Pfizer, NovoNordisk and Zoe Global, has received honoraria from Merck, Pfizer, Novo Nordisk and Eli Lilly, and research funding from Abbvie, Astra Zeneca, Boehringer Ingelheim, Eli Lilly, Janssen, Merck, NovoNordisk, Pfizer, Roche, Sanofi Aventis, Servier, and Takeda; is now an employee of Genentech and a holder of Roche stock.

The views expressed in this article are those of the authors and do not necessarily represent those of: the NHS, the NIHR, or the UK Department of Health; the National Heart, Lung, and Blood Institute, the National Institutes of Health, or the US Department of Health and Human Services. 
medRxiv preprint doi: https://doi.org/10.1101/2020.09.22.20198937; this version posted September $23,2020$. The copyright holder for this preprint (which was not certified by peer review) is the author/funder, who has granted medRxiv a license to display the preprint in perpetuity.

It is made available under a CC-BY 4.0 International license.

\section{LIST OF SUPPLEMENTARY MATERIALS}

Supplementary Materials and Methods

Supplementary Note 1: Summary of loci identified through recent ancestry-specific and trans-ancestry meta-analyses incorporating GWAS from the DIAMANTE Consortium

Supplementary Note 2: Acknowledgements and funding

Supplementary Note 3: Contributors to FinnGen

Figures S1 - S20

Tables S1 - S23 
medRxiv preprint doi: https://doi.org/10.1101/2020.09.22.20198937; this version posted September $23,2020$. The copyright holder for this preprint (which was not certified by peer review) is the author/funder, who has granted medRxiv a license to display the preprint in

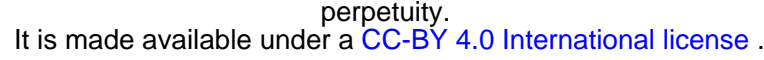

\section{FIGURE LEGENDS}

Figure 1. Comparison of number of SNVs in $99 \%$ credible set for distinct association signals for T2D obtained from European ancestry-specific meta-analysis and trans-ancestry metaregression. Each point corresponds to a distinct association signal, plotted according to the $\log _{10}$ credible set size in the trans-ancestry meta-regression on the $x$-axis and the $\log _{10}$ credible set size in the European ancestry meta-analysis on the y-axis. Trans-ancestry credible sets were derived from meta-regression of 180,834 cases and 1,159,055 controls. European ancestry-specific credible sets were derived from meta-analysis of 80,154 cases and 853,616 controls. (a) We excluded 26 signals that were resolved to a single variant in both trans-ancestry meta-regression and European ancestry-specific meta-analysis. The 266 (85.3\%) signals above the dashed $y=x$ line were more precisely fine-mapped in the transancestry meta-regression. (b) We artificially boosted the effective sample size of the European ancestry-specific meta-analysis to that of the trans-ancestry meta-regression. We considered the 266 signals that were more precisely fine-mapped in the trans-ancestry meta-regression. The 156 (58.6\%) signals above the dashed $y=x$ line were more precisely fine-mapped because of population diversity.

Figure 2. T2D association signal at the BCAR1 locus colocalizes with multiple circulating plasma pQTLs. (a) Signal plot for T2D association from trans-ancestry meta-regression of 180,834 cases and 1,159,055 controls of diverse ancestry. Each point represents a SNV, plotted with their $p$-value (on a $\log _{10}$ scale) as a function of genomic position (NCBI build 37). Gene annotations are taken from the University of California Santa Cruz genome browser. Recombination rates are estimated from the Phase II HapMap. (b) Fine-mapping of T2D association signal from trans-ancestry meta-regression. Each point represents a SNV plotted with their posterior probability of driving T2D association as a function of genomic position (NCBI build 37). Chromatin states are presented for four diabetes-relevant tissues. (c) Schematic presentation of the single cis- and multiple trans-effects mediated by the $B C A R 1$ locus on plasma proteins and the islet chromatin loop between islet enhancer and promoter elements near CTRB2. (d) Signal plots for four circulating plasma proteins that colocalize with the T2D association in 3,301 European ancestry participants from the INTERVAL study. Each point represents a SNV, plotted with their $p$-value (on a $\log _{10}$ scale) as a function of genomic position (NCBI build 37). (e) Expression of genes (transcripts per million, TPM) encoding colocalized proteins in islets, pancreas and whole blood.

Figure 3. Defining causal molecular mechanisms at the PROX1 locus. (a) Signal plot for two distinct T2D associations from trans-ancestry meta-regression of 180,834 cases and $1,159,055$ controls of diverse ancestry. Each point represents a SNV, plotted with their $p$ value (on a $-\log _{10}$ scale) as a function of genomic position (NCBI build 37). Index SNVs are represented by the blue and purples diamonds. All other SNVs are coloured according the LD with the index SNVs in European and East Asian ancestry populations. Gene annotations are taken from the University of California Santa Cruz genome browser. (b) Fine-mapping of T2D association signals from trans-ancestry meta-regression. Each point represents a SNV plotted with their posterior probability of driving each distinct T2D association as a function of genomic position (NCBI build 37). The $99 \%$ credible sets for the two signals are highlighted by the purple and blue diamonds. Chromatin states are presented for four diabetes-relevant tissues. (c) Transcriptional activity of the 99 credible set variants at the 
medRxiv preprint doi: https://doi.org/10.1101/2020.09.22.20198937; this version posted September 23, 2020. The copyright holder for this preprint (which was not certified by peer review) is the author/funder, who has granted medRxiv a license to display the preprint in

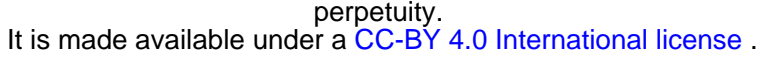

two T2D association signals in human HepG2 hepatocytes and EndoC- $\beta \mathrm{H} 1$ beta cell models obtained from in vitro reporter assays. WT: wild-type (non-risk allele/haplotype). GFP: green fluorescent protein (negative control). EV: empty vector (baseline). (d) Expression of PROX1 (transcripts per million, TPM) across a range of diabetes-relevant tissues.

Figure 4. Transferability of trans-ancestry and ancestry-specific GRS into GWAS across diverse population groups. Each GRS was constructed using lead SNVs attaining genomewide significance ( $p<5 \times 10^{-9}$ for trans-ancestry GRS and $p<5 \times 10^{-8}$ for ancestry-specific GRS). For the trans-ancestry GRS, population-specific allelic effects on T2D were estimated from the meta-regression to generate different GRS weights for each test GWAS. For each ancestry-specific GRS, weights were generated from allelic effect estimates obtained from fixed-effects meta-analysis. The trait variance explained (pseudo $R^{2}$ ) by each GRS was assessed in two test GWAS from each ancestry group. The trans-ancestry GRS outperformed ancestry-specific GRS into all test GWAS, reflecting the shared genetic contribution to T2D across diverse populations, despite differing allele frequencies and LD patterns. 
(a)

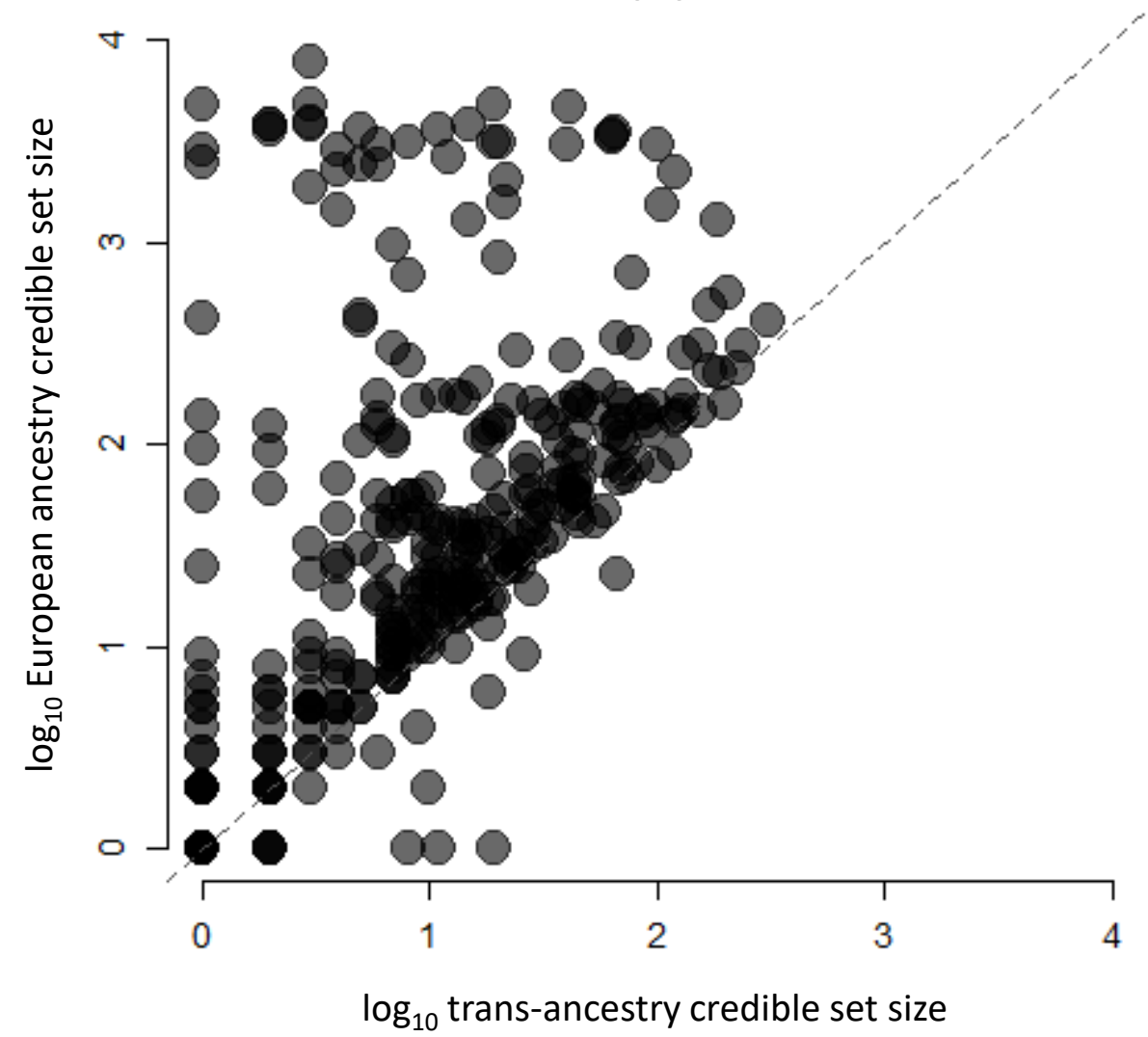

(b)

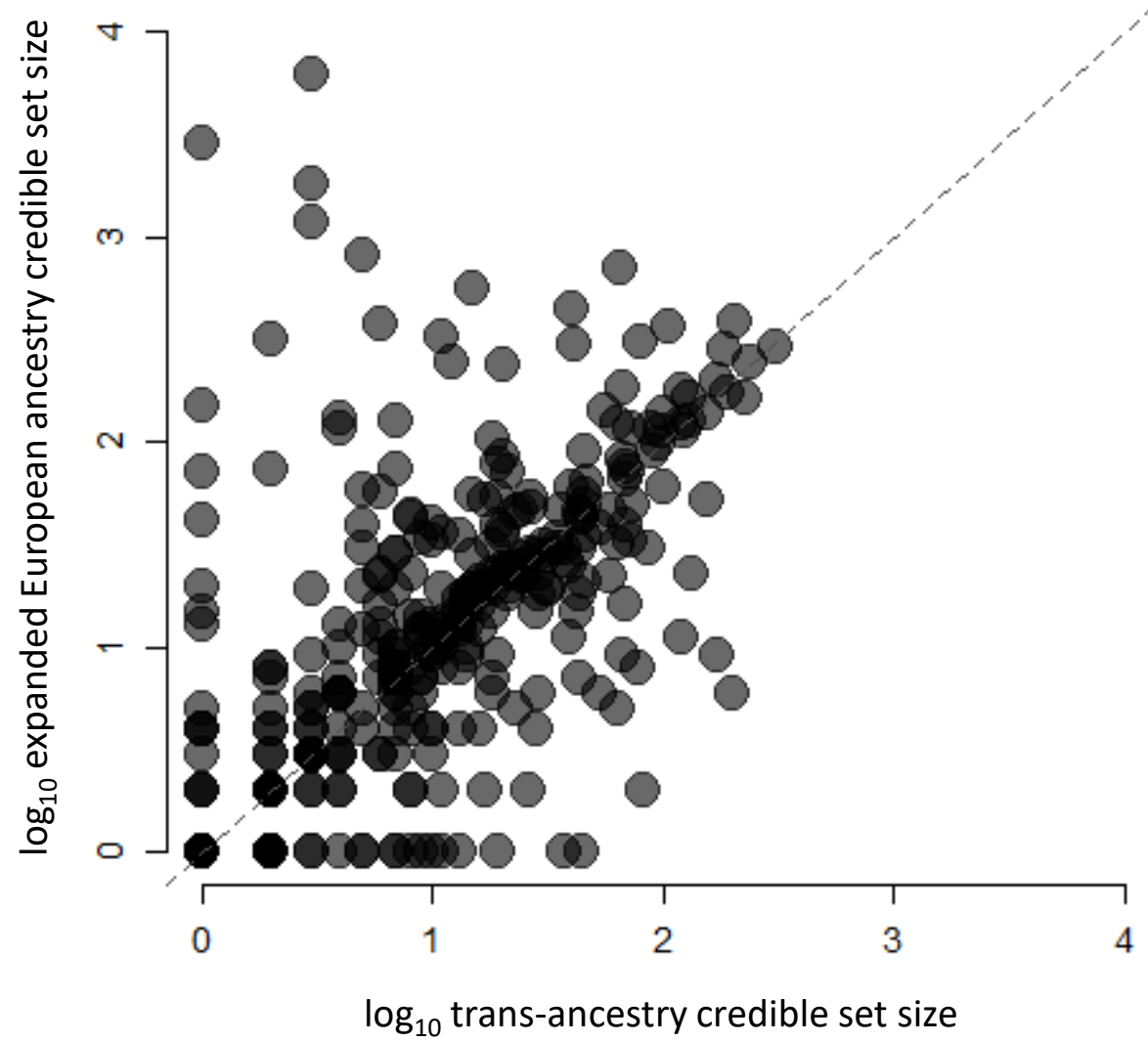


a)

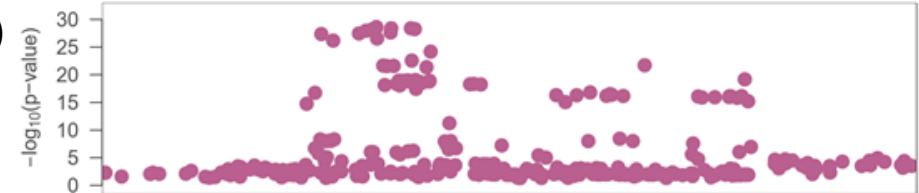

b)

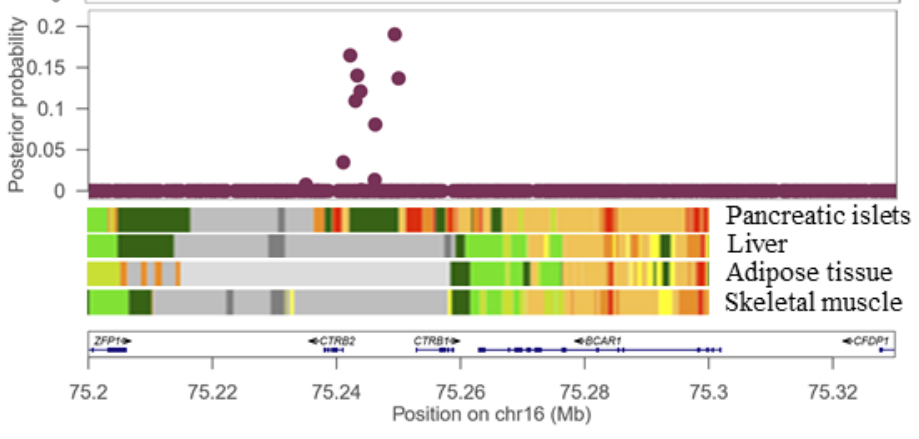

c)

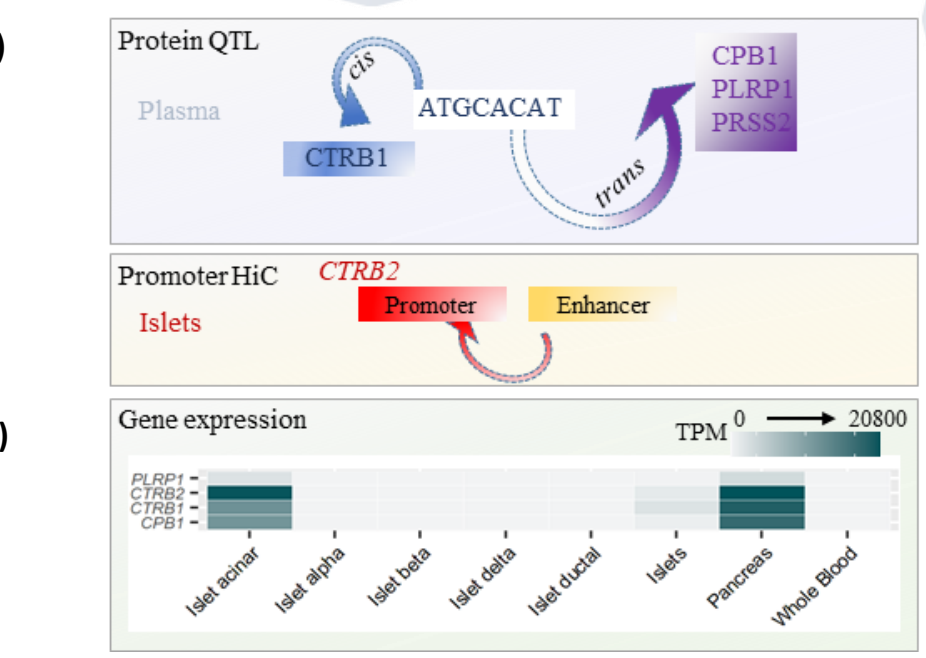

e)
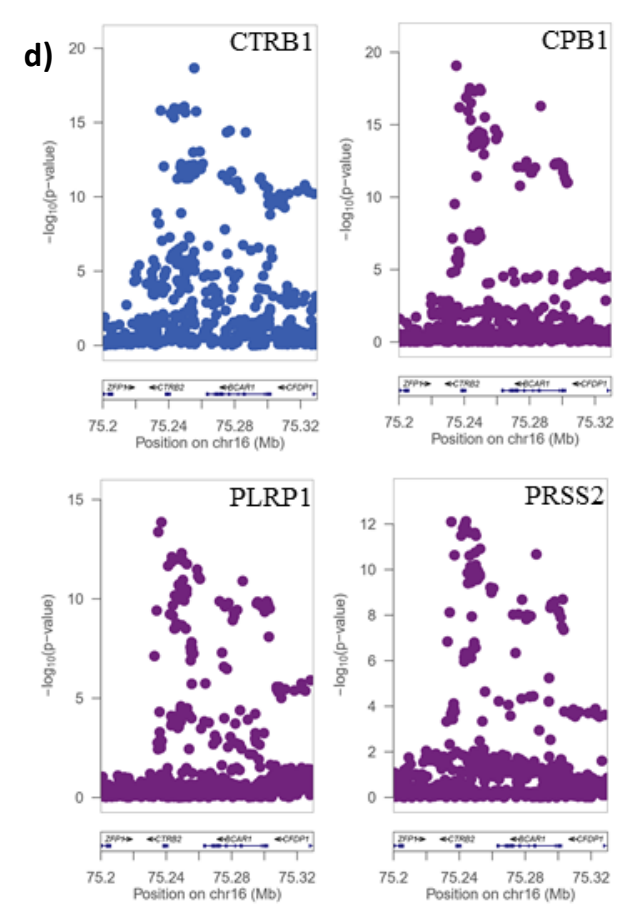
a)
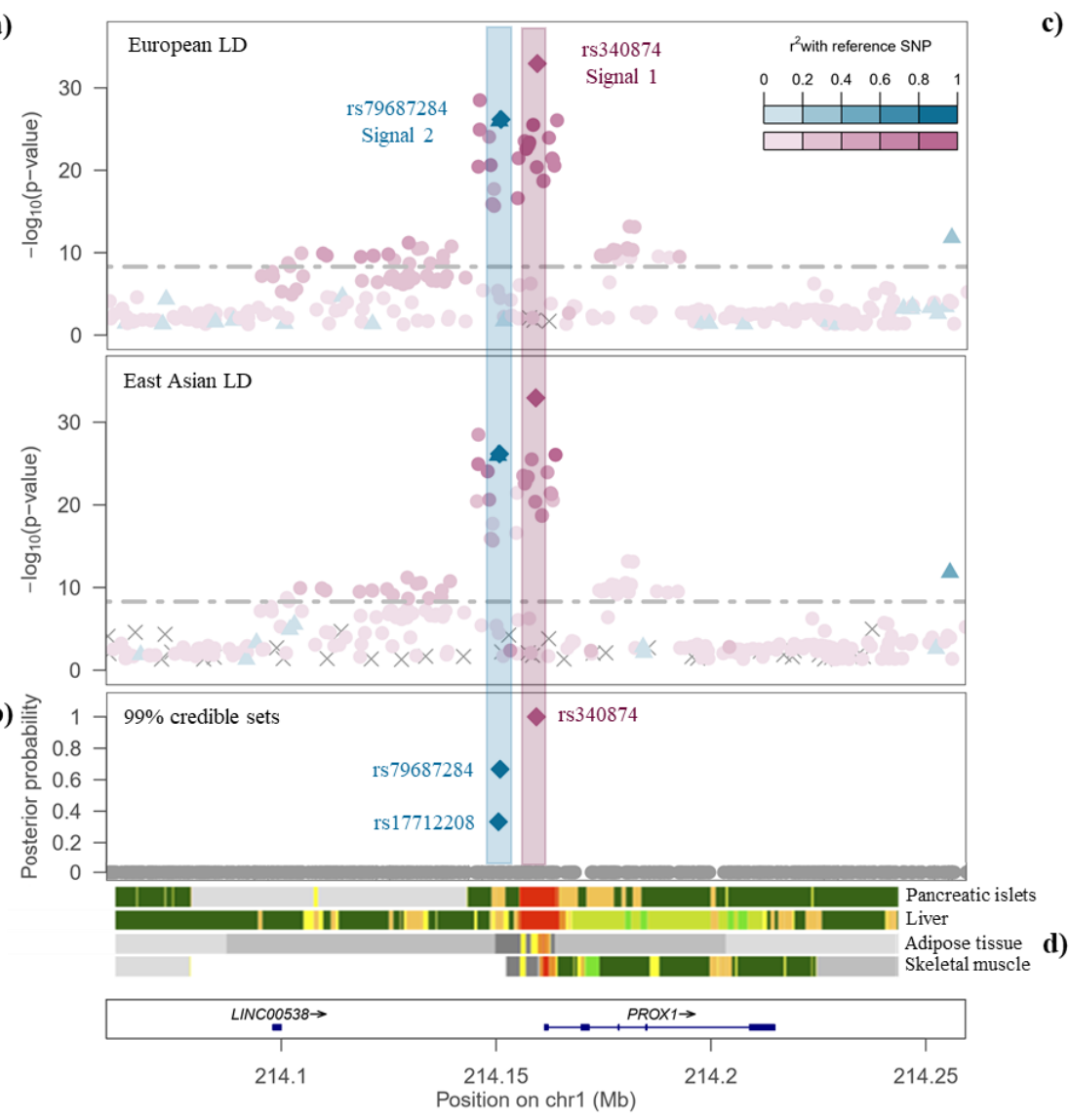

c)
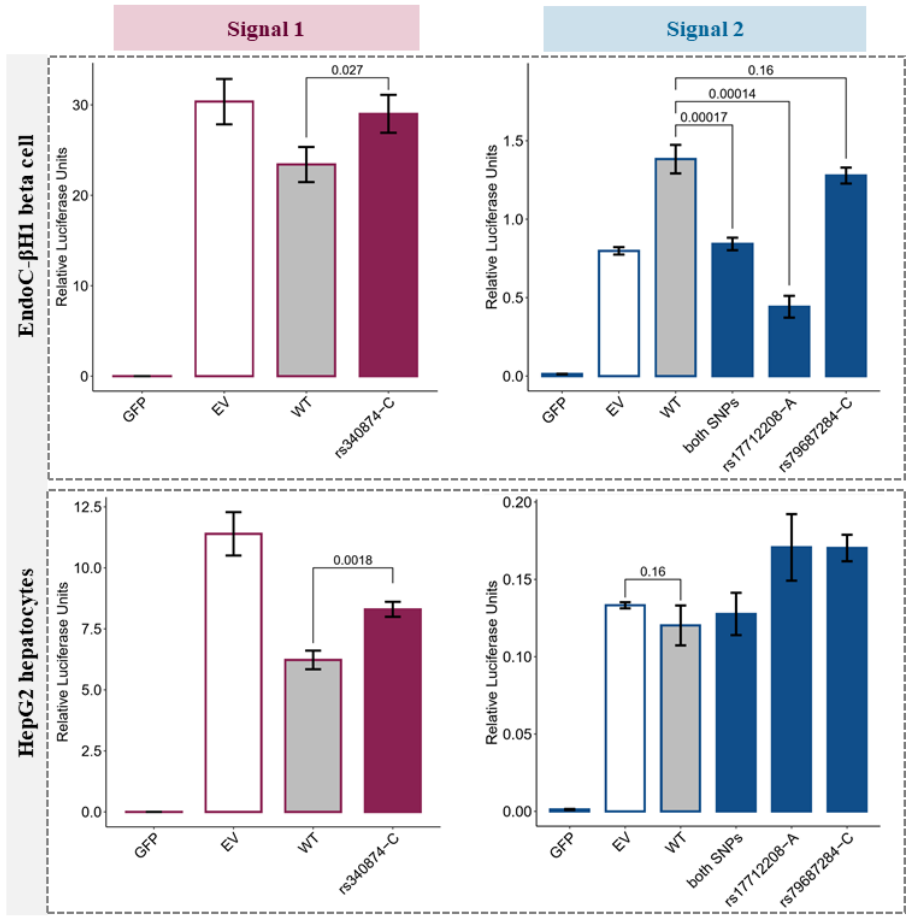

PROXI expression in different tissues

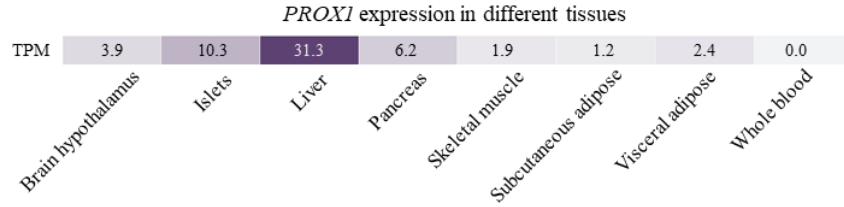



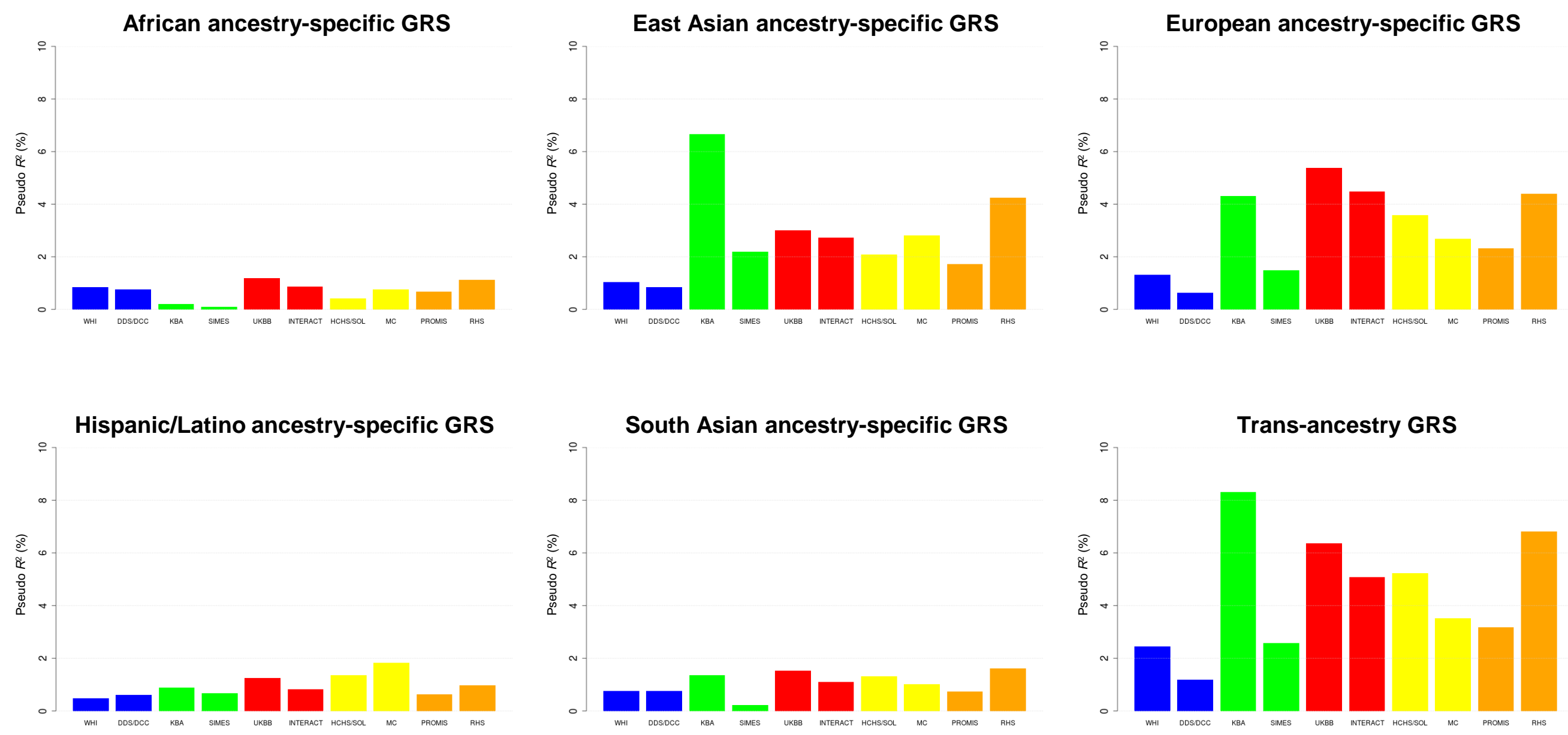

Test GWAS:

African ancestry

East Asian ancestry

European ancestry

Hispanic/Latino ancestry

South Asian ancestry 